\title{
A dynamically evolving war between autophagy and pathogenic microorganisms
}

\author{
Qianqian ZHENG ${ }^{1,2^{*}}$, Liangwei DUAN ${ }^{1,2^{*}}$, Yang ZHANG ${ }^{1,2}$, Jiaoyang $\mathrm{LI}^{1,2}$, Shiyu ZHANG ${ }^{1,2}$, Hui WANG ${ }^{1,2 \bowtie}$ \\ ${ }^{1}$ Henan Key Laboratory of Immunology and Targeted Drugs, School of Laboratory Medicine, Xinxiang Medical University, Xinxiang 453003, China \\ ${ }^{2}$ Henan Collaborative Innovation Center of Molecular Diagnosis and Laboratory Medicine, Xinxiang Medical University, Xinxiang 453003, China
}

\begin{abstract}
Autophagy is an intracellular degradation process that maintains cellular homeostasis. It is essential for protecting organisms from environmental stress. Autophagy can help the host to eliminate invading pathogens, including bacteria, viruses, fungi, and parasites. However, pathogens have evolved multiple strategies to interfere with autophagic signaling pathways or inhibit the fusion of autophagosomes with lysosomes to form autolysosomes. Moreover, host cell matrix degradation by different types of autophagy can be used for the proliferation and reproduction of pathogens. Thus, determining the roles and mechanisms of autophagy during pathogen infections will promote understanding of the mechanisms of pathogen-host interactions and provide new strategies for the treatment of infectious diseases.
\end{abstract}

Key words: Autophagy; Pathogenic microorganism; Bacteria; Virus; Fungi; Parasite

\section{Introduction}

Cellular autophagy is a type of subcellular degradation pathway that is vital to maintain the health of eukaryotes (Chun and Kim, 2018; Schille et al., 2018; Allen et al., 2020; Andriantsitohaina and Papon, 2020). Cellular autophagy refers broadly to the process of lysosome-mediated cytoplasmic degradation (Wang and Qin, 2013). Compared with the proteasome, the lysosome has a more powerful degradation ability. Therefore, the cellular autophagy pathway can degrade intracellular substances from soluble proteins to intact organelles in large quantities, and has advantages for the degradation of long-lived macromolecules and damaged organelles (Chang et al., 2013; Chen G et al., 2014; Kocaturk and Gozuacik, 2018). Cellular autophagy has important roles in growth and development, immune defense, programmed cell death, tumor suppression, and neuropathological inhibition (Mestre and Colombo,

\footnotetext{
$\triangle$ Hui WANG, wanghui@xxmu.edu.cn

The two authors contributed equally to this work

(i) Qianqian ZHENG, https://orcid.org/0000-0002-1760-4906

Liangwei DUAN, https://orcid.org/0000-0001-9728-3251

Hui WANG, https://orcid.org/0000-0002-2454-3814
}

Received Mar. 21, 2021; Revision accepted July 5, 2021; Crosschecked Dec. 9, 2021

(C) Zhejiang University Press 2022
2012; Chew et al., 2015; Tian et al., 2015; Yin et al., 2016; Dai and Zhu, 2020; Wen et al., 2020).

Depending on the method of wrapping the intracellular material and the mode of delivery, cellular autophagy can be classified into macro-autophagy, microautophagy, and chaperone-mediated autophagy (Glick et al., 2010; Feng et al., 2014; Farré and Subramani, 2016). Macro-autophagy wraps intracellular material by forming an autophagosome with a bilayer membrane structure, which eventually fuses with a lysosome (Feng et al., 2014; Fujioka et al., 2020). Micro-autophagy directly engulfs specific organelles through deformation of the lysosome or vesicle surface (Mijaljica et al., 2011; Schuck, 2020). Chaperone-mediated autophagy introduces cytoplasmic or organelle proteins into the lysosome lumen through unfolding via molecular chaperones (Kaushik and Cuervo, 2018; Tekirdag and Cuervo, 2018).

This review focuses on macro-autophagy (referred to hereafter as autophagy). Autophagy is a complex process. First, the Unc-51-like autophagy activating kinase 1 (ULK1) complex mediates the initiation of autophagy (Zachari and Ganley, 2017). When cells are in a normal physiological state, intracellular energy is sufficient, and the mammalian target of rapamycin complex 1 (mTORC1) is in an activated state to 
promote the phosphorylation of autophagy-related 13 (ATG13) and ULK1 to inactivate the ULK1 complex, but when cells are under starvation conditions, mTORC1 activity is inhibited (Li and Yan, 2019). Intermolecular interactions, such as dephosphorylation of ATG13 and ULK1, promote the formation of the active ULK1 complex and initiate autophagy (Joo et al., 2011; Richards and Jackson, 2012; Kamber et al., 2015; Kandul et al., 2016). Second, the activated ULK1 complex phosphorylates the phosphatidylinositol 3-kinase catalytic subunit type 3 (PI3KC3) complex to mediate the formation of the pre-autophagosome structure (PAS) of the endoplasmic reticulum, Golgi apparatus, and other membranous organelles (Kim et al., 2011; Kato et al., 2019; Kawabata and Yoshimori, 2020). The PI3KC3 complex further recruits the ATG16L1 complex, and both are co-located on the outer membrane surface of the PAS and promote its expansion (Kirkin and Rogov, 2019). Then, ATG4 cleaves the microtubule-associated protein 1 light chain $3 \alpha$ (LC3) precursor to form LC3-I, which is delivered to the autophagic vesicles, under the action of E1-like enzyme ATG7 and E2-like enzyme ATG3, by covalent conjugation of phosphatidylethanolamine (PE) into LC3-II (Tanida et al., 2008; Kourtis and Tavernarakis, 2009; Kobayashi et al., 2015). LC3-II then participates in the extension of the membrane of the autophagosome. LC3-II can further combine with the newly formed autophagic membrane to promote the fusion and expansion of autophagosomes (Lee and Lee, 2016). Finally, the endosomal sorting complex required for transport (ESCRT) complex, soluble $\mathrm{N}$ ethylmaleimide-sensitive factor attachment protein receptor (SNARE) complex, and Rab guanosine triphosphatases (GTPases) mediate the movement of autophagosomes along the microtubule framework. The autophagosomes then fuse with lysosomes to form autophagolysosomes, whose contents and inner membrane are degraded by lysosomal enzymes (Towers and Thorburn, 2016; Kumsta et al., 2017). Autophagy plays an important role in the regulation of physiological activities, such as the reconstruction of cell structures and the maintenance of normal growth and differentiation, as well as the process of resisting adverse external environments (Mizushima and Komatsu, 2011; Cardenal-Muñoz et al., 2017).

It was believed that autophagy did not selectively degrade substrates (Reggiori et al., 2012). However, increasing autophagy-related research has shown that under certain circumstances, autophagy can specifically degrade certain types of macromolecules or organelles in a process known as selective autophagy (Farré and Subramani, 2016). The pathways of selective autophagy include the cytoplasm-to-vacuole targeting (Cvt) pathway, mitochondrial autophagy, endoplasmic reticulum autophagy, peroxisomal autophagy, ribosomal autophagy, and lipid autophagy (Yuan et al., 1999; Kamada et al., 2000; Shintani and Klionsky, 2004b; Narendra et al., 2008). In essence, cellular autophagy comprises type II programmed cell death. The reasons that cells are selected as targets for autophagy vary, and include cellular senescence and invading exogenous pathogens. Numerous studies have shown that selective autophagic pathways can also destroy these invading pathogens (Deretic and Levine, 2009). These processes are known as xenophagy (Bauckman et al., 2015). Xenophagy is closely related to innate immunity and its receptor is typified by sequestosome-1/p62-like receptors (SLRs) (Deretic, 2012). These act as pattern recognition receptors (PRRs) and usually have one or more LC3interacting region (LIR) structural domains, including sequestosome-1 (SQSTM1, also known as p62), optineurin (OPTN), neighbor of BRCA1 gene 1 (NBR1), and nuclear dot protein 52 (NDP52) (Levine, 2005; Deretic, 2012). These proteins function as autophagy adaptor proteins, which are capable of directly capturing bacteria, producing and transporting antimicrobial peptides, and acting as inflammatory signals to promote autophagy, thereby clearing pathogens from invading cells. In virophagy (a form of xenophagy), the pathogenassociated molecular pattern (PAMP) of the virus is recognized by intracellular PRRs, including retinoic acid-inducible gene I (RIG-I) like receptors (RLRs), nucleotide-binding and oligomerization domain (NOD)like receptors (NLRs), and Toll-like receptors (TLRs) (Cadwell, 2016; Choi et al., 2018). After pathogen recognition and binding, they induce apoptosis or autophagy, modulate and regulate inflammatory responses, and activate specific signaling pathways (Cadwell, 2016).

When cells are invaded by various microbial pathogens (mainly bacteria, viruses, fungi, or parasites), intracellular pathogens are usually endocytosed by host cells and then enter the cytoplasm. There, the host cells initiate the autophagic pathway, and autophagic vesicles wrap pathogens and transport them to lysosomes 
for degradation (Lin et al., 2021). However, recent studies have revealed that certain pathogenic factors have evolved multiple strategies to interfere with the autophagic signaling pathway, enabling or inhibiting the fusion of autophagosomes with lysosomes to form autophagolysosomes to evade autophagic degradation, or even using autophagy to promote their own replication (Kimmey and Stallings, 2016; Coppens, 2017; Abdoli et al., 2018; Xiong et al., 2019; Hu et al., 2020). Therefore, it is important to determine the relationship between host cell autophagy and various pathogenic factors to clarify the pathogenic mechanisms of pathogens.

In this review, we focus on important progress in research on the interaction between autophagy and pathogenic microorganisms, and describe the direct scavenging effect of various regulations of autophagic signaling pathways on pathogenic factors. In addition, we provide an overview of the mechanisms used by pathogenic microorganisms to evade or use autophagy for themselves, thereby promoting their own survival. These could provide a reference for autophagy research and reveal new routes for effective anti-infective therapies targeting autophagy.

\section{Bacteria and autophagy}

Autophagy can act as an innate immune mechanism against bacterial infection (Ogawa et al., 2011; $\mathrm{Hu}$ et al., 2020). For healthy cell growth, invading bacteria are recognized by the SLRs and the selective autophagy pathway (xenophagy) removes invading extracellular bacteria, as well as bacteria colonized in the cytoplasm, phagosomes, or vesicles. However, this method of killing bacteria is not perfect. By interfering with the processes associated with autophagy, the bacteria's innate aim to survive can be achieved. This interference process can begin with the fusion of pathogenic bacteria-infested autophagosomes with lysosomes. Maturation of the autophagosomes to autophagic lysosomes is then delayed by the secretion of associated proteins, which remain in the vesicles of autophagosome-like structures as a resource for bacterial proliferation or survival. Alternatively, in macrophages, bacterially secreted proteins promote the formation of autophagosome-like structures or interfere with the maturation of autophagosomes, which in turn allows the pathogens themselves to survive (Deretic, 2010; Bah and Vergne, 2017; Sudhakar et al., 2019; Hu et al., 2020).

Autophagy plays an important role in the interaction between pathogenic bacteria and host cells. After bacterial infection of host cells, the results of the interaction between autophagy and bacteria include preventing bacterial proliferation or autophagy interacting with other immune factors (such as inflammatory factors and interferon- $\gamma($ IFN- $\gamma)$ ) to control bacterial infection (Desai et al., 2015). Bacteria use their virulence factors, synthesize messenger RNA (mRNA), or secrete certain proteins and lipids to block the autophagy process or induce incomplete autophagy processes, thereby evading the killing effect of autophagy.

\subsection{Gram-positive bacterial infection and autophagy}

Current research has focused mainly on pathogenic Gram-positive bacteria, such as Staphylococcus aureus, group A Streptococcus (GAS), and Listeria monocytogenes.

S. aureus infection can cause septic and toxic diseases (Otto, 2014). S. aureus is rapidly ubiquitinated upon invasion of human cervical cancer (HeLa) cells and induces cellular autophagy by binding to the autophagy receptor proteins SQSTM1, NDP52, and OPTN, which are marked by the formation of an apparent co-localization of $S$. aureus with LC3. However, the fusion of autophagosomes and lysosomes is blocked and complete autophagic flux cannot be performed (Schnaith et al., 2007). S. aureus can evade autophagy by activating certain proteins or signaling pathways. After infection of murine fibroblasts and human keratinocytes, it activates mitogen-activated protein kinase 14 (MAPK14), which then phosphorylates autophagy-related 5 (ATG5) to inhibit the fusion of autophagosomes and lysosomes to avoid autophagic degradation (Keil et al., 2013; Neumann et al., 2016) (Fig. 1).

In addition, the autophagy caused by $S$. aureus infection of the mouse macrophage cell line RAW264.7 is closely related to the PI3K/protein kinase B (AKT)Beclin1 signaling pathway (Lv et al., 2019). After inhibiting this signaling pathway, the level of S. aureusinduced autophagy is significantly downregulated (Lv et al., 2019). These observations have shown that because the autophagosomes that occur in $S$. aureusinfected cells cannot fuse with lysosomes, incomplete 




Fig. 1 Interaction between autophagy and bacteria. After Staphylococcus aureus invades host cells, it is rapidly ubiquitinated and associates with autophagy receptors sequestosome-1 (SQSTM1), nuclear dot protein 52 (NDP52), and optineurin (OPTN) to induce autophagy. $S$. aureus can inhibit the fusion of the autophagosome and lysosome by activating mitogen-activated protein kinase 14 (MAPK14) and phosphorylating autophagy-related 5 (ATG5) to avoid autophagic degradation. PI3P: phosphatidylinositol 3-phosphate; ULK1: Unc-51-like autophagy-activating kinase 1; TORC1: target of rapamycin complex 1; CALCOCO2: calcium-binding and coiled-coil domain 2; LC3: microtubuleassociated protein 1 light chain $3 \alpha$; Ub: ubiquitin.

autophagy is triggered. This prevents the autophagosomes from being acidified, thereby allowing $S$. aureus to proliferate in the autophagosome without being degraded (Schnaith et al., 2007) (Fig. 1).

The manipulation of autophagy by $S$. aureus to avoid being killed is well documented. $S$. aureus secretes the virulence factor pore-forming toxin $\alpha$-hemolysin (Hla), which activates autophagy in a different way. This leads to a decrease in intracellular cyclic adenosine monophosphate (cAMP) levels and promotes a nonclassical autophagic pathway. This autophagic pathway requires the involvement of ATG5, which is essential for the development of autophagosomal membranes. $S$. aureus can be present in the autophagosome, preventing its maturation and fusion with the lysosome. Subsequently, S. aureus escapes from autophagosomes and enters the cytoplasm where it replicates prolifically, leading to the death of the host cell and the infection of neighboring cells (Mestre et al., 2010).
GAS are pathogenic bacteria that exist widely in nature (Okamoto and Nagase, 2018). After GAS invade a host cell, most of the GAS in the cytoplasm are encapsulated in GAS-containing autophagosomelike vacuoles (GcAVs) and degraded through the autophagy pathway (Nakagawa et al., 2004). In $\operatorname{Atg} 5^{-1-}$ mouse embryo fibroblasts (MEFs), which cannot form autophagosomes, GAS can survive, proliferate, and be released from the cells (Nakagawa et al., 2004). Autophagy can inhibit the growth and proliferation of GAS. To survive in the cell for a long time, GAS have evolved a variety of strategies to evade autophagy. For example, they use certain virulence factors to avoid autophagy degradation. Streptococcus pyrogenic exotoxin B (SpeB) is a cysteine protease secreted by Streptococcus (Hytönen et al., 2001). The M1T1 serotype GAS use SpeB to degrade SQSTM1, NDP52, and NBR1 proteins in the host cell cytoplasm and prevent recognition of host cell autophagy-related proteins (Barnett 
et al., 2013). Streptolysin O (SLO) is a member of the cholesterol-dependent pore-forming cytolysin conserved family (Vita et al., 2020). GAS use SLO to form pores in the newly formed endosomal membrane to help them escape into the cytoplasm (Sakurai et al., 2010). By activating $\beta 1$ integrin, SLO recruits nicotinamide adenine dinucleotide phosphate (NADPH) oxidase 2 (NOX2), produces reactive oxygen species (ROS), and induces ineffective LC3-related phagocytosis (LAP), leading to insufficient acidification to evade host autophagic clearance and promoting the proliferation of GAS (Lu et al., 2015; Cheng et al., 2019).

L. monocytogenes is a zoonotic pathogen and a facultative intracellular bacterium, which is used as a model intracellular parasite (Lecuit, 2020). Upon infection with $L$. monocytogenes, host cells activate autophagy through their own recognition receptors. $\beta 2$ integrin/macrophage-1 antigen (MAC-1) is a receptor expressed by macrophages that recognizes a variety of microbial ligands (Ehlers, 2000). Host cell MAC-1 induces LAP by activating acid sphingomyelinase (ASMase) and NADPH oxidase Nox2 to generate ROS (Gluschko et al., 2018). In addition, LAP promotes the fusion of Listeria-containing phagosomes and lysosomes, thereby enhancing the anti-bacterial ability of macrophages and the host's immune response (Gluschko et al., 2018). TLR2 is involved in the autophagy process produced by Listeria. In $\mathrm{Tlr} 2^{-/}$macrophages, Listeria and LC3 cannot co-localize, and further studies have shown that TLR2 participates in this autophagy process through its downstream extracellular signal-regulated kinase (ERK) signaling pathway (Anand et al., 2011). After invading the host cell, L. monocytogenes, like GAS, is able to use its virulence factors to assist its escape from the autophagosome, and then enters the cytoplasm to continue its proliferation. Its virulence factor, L. monocytogenes Lysin O (LLO), is a cholesterol-dependent pore-forming cytolysin (Anand et al., 2011). In the early stages of infection, Listeria enters macrophages but its replication is inhibited by autophagy induced by LLO (Birmingham et al., 2007; Py et al., 2007). For a period of time after infection, with the help of two bacterial phospholipases C (PLCs), a phosphatidylinositolspecific PLC (PI-PLC, encoded by plcA) and a broadrange PLC (PC-PLC, encoded by plcB), Listeria escapes from the autophagosome (Birmingham et al.,
2007). LLO binds to cholesterol, inserts into the host cell membrane, and aggregates to form pores to facilitate the escape of Listeria from the cell. Therefore, the autophagy response induced by LLO exhibits dynamic changes over time during Listeria infection.

Actin assembly-inducing protein A (ActA) is also a virulence factor of Listeria, and plays an important role in autophagy escape. ActA shields bacteria from recognition by autophagy by recruiting the actin-related protein 2/3 (Arp2/3) complex and the extractable nuclear antigen/vasodilator-stimulated phosphoprotein (Ena/ VASP) to the bacterial surface to form an artifact. The camouflage provided by these proteins prevents bacteria from being recognized by autophagy (Yoshikawa et al., 2009; Cheng et al., 2018).

Listeria evades autophagy mainly through PlcA and ActA (Rudnicka et al., 1997; Mitchell et al., 2015). PlcA blocks the binding of PE to LC3 and presumably acts by preventing the formation of PI3P (Mitchell et al., 2015). The internalin $\mathrm{K}$ ( $\mathrm{InlK}$ ) is recognized by decorating the bacterial surface with the major vault protein (MVP) to escape autophagy. The InlK-MVP interaction is a two-part process along the same pathway as actin polymerization. InlK recruits MVP to the bacterial surface, followed by ActA replacing InlK, and actin replaces MVP to modify the bacterium, preventing the recruitment of ubiquitin (Ub), the recognition of p62, and the recruitment of LC3 as a means of evading cellular autophagy (Dortet et al., 2011).

Mycobacterium tuberculosis (MTB) is an intracellular parasitic bacterium (Yi et al., 2020). Cellular autophagy of MTB is an important anti-MTB response mechanism, operating either directly through the formation of autophagic lysosomes or indirectly through the upregulation of intrinsic immunity (Zhai et al., 2019). MTB infection-induced autophagy in macrophages enhances the acidification and maturation of Mycobacterium-containing phagosomes, thereby inhibiting the survival of intracellular MTB (Queval et al., 2017). There is also a mechanism by which MTB inhibits autophagy in macrophages, thereby avoiding being killed (Maphasa et al., 2021). MTB can inhibit the maturation and acidification of autophagosomes and thus avoid clearance via autophagy. Inhibition of macrophage phagosome and lysosome binding is one of the main mechanisms by which MTB inhibits the maturation of phagosomes (Zhai et al., 2019). After capturing MTB, autophagic vesicles fuse with lysosomes 
to transport the bacteria into an acidic environment filled with hydrolytic enzymes and free radicals. Impaired lysosome function increases susceptibility to MTB infection by inhibiting macrophage autophagy and the ability to migrate directionally. The killing of MTB by autophagic lysosomes is associated with p62, which transports ribosomal precursors and other ubiquitinated proteins from the cytoplasm into autophagic lysosomes for degradation to produce new antimicrobial peptides (Deretic, 2012).

\subsection{Gram-negative bacterial infection and autophagy}

Current studies have focused mainly on the Gramnegative pathogen Salmonella, which causes mainly gastroenteritis in humans and mammals and contains two Type III secretion systems (T3SSs), Salmonella virulence island 1 (SPI-1) and SPI-2 (Kim et al., 2018). SPI-1 is essential for invasion by Salmonella, and SPI-2 promotes its survival in the host cell (Jennings et al., 2017). Phagocytic vesicles inhibited by Salmonella are called Salmonella-containing vacuoles (SCVs) (Stévenin et al., 2019). Most Salmonella strains exist in SCVs, and only a fraction escapes from SCVs to replicate in the cytoplasm. Autophagy acts on Salmonella in two ways. First, Salmonella escaped from SCVs are ubiquitinated. Ubiquitination modification recruits a variety of autophagy adaptor proteins, including SQSTM1/p62, NDP52, and OPTN (Kishi-Itakura et al., 2020). These proteins bind to ubiquitinated bacteria through their Ub-binding domains. Then, new autophagosomes are attached through interactions with the ATG8 family members anchored in the autophagosome membrane. Salmonella-containing autophagosomes are fused with lysosomes and Salmonella is then killed in a hydrolytic environment (Mostowy, 2013). Second, SCVs are punctured via SPI-1, causing the damaged SCVs to be recognized by the autophagy machinery. In this case, Salmonella does not need to enter the cytoplasm to be captured by autophagy (Birmingham et al., 2006). The formation of pores in SCVs by SPI-1 leads to the accumulation of multiple cytoplasmic galectins, such as galectin-8, which monitors the integrity of intracellular lysosomes (Thurston et al., 2012). SCV is modified by galectin- 8 to recruit Ub ligases and NDP52 to the cell membrane, leading to SCV components being cleared via autophagy (Ravenhill et al., 2019).

Autophagic recognition of bacteria is usually associated with ubiquitination, and the E3 ligase could play a significant role in cellular autophagy by mediating ubiquitination. Human leucine-enriched sterile $\alpha$ motif containing 1 (LRSAM1) recognizes and ubiquitinates Salmonella typhimurium in the cytoplasm of HeLa cells through its leucine-rich repeat (LRR) domain and really interesting new gene (RING) domain, respectively, and initiates Ub-dependent autophagy, thereby restricting $S$. typhimurium infection (Huett et al., 2012). In addition, the E3 ligase linear ubiquitin chain assembly complex (LUBAC) produces linear polyubiquitin chains on the surface of $S$. typhimurium, recruiting receptors OPTN, NDP52, and SQSTM1/p62, thereby limiting its proliferation (Noad et al., 2017). Besides, the RING-between-RING E3 ligase Ariadne-1 homolog (ARIH1) can directly target $S$. typhimurium to autophagosomes (Polajnar et al., 2017). Depletion of LRSAM1 and ARIH1 after S. typhimurium infection leads to enhanced LUBAC-dependent ubiquitination. However, this does not inhibit its growth in the cytoplasm (Polajnar et al., 2017). These findings highlight that host cells can initiate autophagy by recruiting different E3 Ub ligases on the surface of bacteria to prevent the cellular proliferation of S. typhimurium.

Legionella pneumophila is a Gram-negative pathogen that can cause lethal pneumonia or influenzalike symptoms in humans (Huss et al., 2020). Immediately upon entry into the host cell phagosome, ATG7 binds to the bacteria and then to ATG8 to form Legionella-containing vacuoles (LCVs). LCVs can fuse with endoplasmic reticulum-derived vesicles, facilitating the replication of $L$. pneumophila within them, a process that requires the involvement of Rasrelated proteins Rab1 and Sec22b (Kagan et al., 2004).

The SNARE protein Syntaxin 17 plays an important role in autophagosome membrane formation by recruiting ATG14L to the endoplasmic reticulummitochondrial binding site to aid in the formation of autophagosomes (Hamasaki et al., 2013). In addition, Syntaxin 17 is essential for the fusion of autophagosomes and lysosomes, and its function is dependent on its C-terminal hairpin structure (Itakura et al., 2012). The effector protein of L. pneumophila, Lpg1137, is a serine protease that cleaves Syntaxin 17, thereby blocking autophagy from occurring (Arasaki et al., 2017). In addition, the RavZ protein blocks the binding of the ATG8 (LC3) protein to PE on the autophagosome membrane by hydrolyzing the amide bond between the glycine residue at the ATG8 C-terminus and the 
adjacent aromatic residue (Choy et al., 2012). This prevents ATG from lipidating and forming an LC3-PE form to aggregate in the vesicle, thereby blocking autophagosome formation (Xie et al., 2008).

\section{Viruses and autophagy}

Viruses are an important class of pathogens that are unique in that once they leave the host cell, they have no replication, transcription, or translation functions. Autophagy plays a key role in viral infections, first as an antiviral process, and second in the possible radicalization of the virus when antiviral methods fail. Some viruses hijack the autophagic machinery to survive within the cell, while others express specific proteins to evade autophagy and multiply within the host cell (Orvedahl and Levine, 2008; Ploen and Hildt, 2015; Zhao et al., 2020). In short, viruses in host cells need to avoid the negative effects of apoptosis and autophagy as far as possible to prolong their life activities, such as replication and spread.

\subsection{Antiviral effects of autophagy}

Autophagy acts not only as a metabolic pathway to maintain intracellular homeostasis, but also as part of the body's immune defense against viruses. After a virus has invaded a cell, the cell transports the virus proteins, nucleic acids, and viral particles through autophagy to the lysosome for degradation, thereby maintaining the health of the body. This involves both innate and adaptive immunity (Choi et al., 2018).

Innate immunity is the body's first line of defense against invasion by exogenous microorganisms and is achieved through the recognition and binding of specific molecular structures of pathogenic microorganisms by membrane-bound PRRs and cytoplasmic PRRs. This activates downstream signaling pathways to produce type I IFN, type III IFN, pro-inflammatory cytokines, and chemokines, enabling the body to establish an antiviral state (Mogensen and Paludan, 2001; Farag et al., 2020). TLRs are classical PRRs that recognize a wide range of viral nucleic acids and transmit signals to myeloid differentiation factors 88 (MyD88) by recruiting Toll/interleukin-1 receptor domain-containing adapter protein inducing IFN- $\beta$ (TRIF) or MyD88, signaling to the downstream nuclear factor- $\mathrm{\kappa B}(\mathrm{NF}-\mathrm{\kappa B})$ signaling pathway, and synthesizing inflammatory factors and IFN regulatory factors (IRFs) to promote IFN production. In this process, TLRs can induce TRIF or MyD88 to interact with Beclin1, which disrupts the binding of Beclin1 to B-cell lymphoma 2 (BCL-2) and thus promotes autophagy (Shi and Kehrl, 2008). Autophagy can also be activated directly by PAMPs and transmit PAMP signals to TLRs to induce an immune response. RLRs are located in the cytoplasm and are responsible for the recognition of specific structures not found in normal cellular RNA, such as the 5'- end triphosphate of viral double-stranded RNA (dsRNA). The RLRs, upon sensing the presence of a virus, can interact with the mitochondrial antiviral signal (MAVS) through the caspase recruitment domain (CARD), which in turn activates the IRF3 and IRF7 and the NF- $\mathrm{kB}$ signaling pathway. A number of receptor molecules in cells that sense DNA virus invasion can also interact with the autophagic pathway. Cyclic guanosine monophosphate (GMP)-AMP (cGAMP) synthase (cGAS) recognizes DNA viruses and synthesizes cGAMP. Stimulator of IFN response cGAMP interactor 1 (STING) then binds to cGAMP to activate downstream related regulatory factors and induce NF- $\mathrm{kB}$ activation. In addition, the endoplasmic reticulum-Golgi intermediate compartment (ERGIC), containing STING, can provide a membrane source for lipidation of LC3, thereby facilitating the clearance of cytoplasmic DNA viruses via autophagy. By contrast, during herpes simplex virus 1 (HSV-1) infection, Beclin1 interacts with cGAS to inhibit cGAMP synthesis and IFN production. This enhances autophagy-mediated degradation of cytoplasmic pathogen DNA to prevent excessive activation of cGAS and sustained immune stimulation. Thus, in addition to being regulated by signals such as cGAS-STING, autophagy or autophagy-related proteins can in turn negatively regulate related signaling pathways (Gui et al., 2019; Liu et al., 2019; Zhang et al., 2020).

Antigen delivery is a transitional phase in the shift from innate to adaptive immunity, which is activated by peptide fragments on the major histocompatibility complex (MHC) on antigen-presenting cells (APCs), followed by recognition of antigens by $\mathrm{T}$ cells (Wieczorek et al., 2017). It is expressed in all nucleated cells, and viral proteins can be delivered to cluster of differentiation 8-positive $\left(\mathrm{CD}^{+}\right) \mathrm{T}$ cells via MHC-I-like molecules after being degraded by the proteasome into immunogenic peptides. Autophagy limits the delivery 
of MHC-I-like molecules by mediating their internalization and degradation. Inactivation of the autophagy factors ATG5 and ATG7 in dendritic cells (DCs) can lead to an increase in the expression of MHC-I on the cell surface, making the body more susceptible to the expression of MHC-I in influenza A virus (IAV) and lymphocytic choriomeningitis virus (LCMV) infection to induce a more intense $\mathrm{CD} 8^{+} \mathrm{T}$ cell immune response (Loi et al., 2016). In contrast, autophagosomes are constitutively formed in MHC-II-positive APCs, such as DCs, B cells, and epithelial cells. They capture extracellular antigens and deliver them to autophagosomes, which deliver antigens from the cytoplasm to MHC by fusing with MHC-II-containing intranuclear body compartment (MIIC)-like molecules. These in turn are then delivered to $\mathrm{CD}^{+} \mathrm{T}$ cells. Studies have shown that human immunodeficiency virus (HIV)infected DCs can use LC3 fusion proteins to specifically target HIV antigens to autophagosomes, effectively enhancing and broadening the immune response of $\mathrm{CD}^{+} \mathrm{T}$ cells, thereby facilitating an endogenous MHC-II-restricted presentation (Coulon et al., 2016). In addition, autophagy mediates cross-antigen presentation of MHC-I and MHC-II types in APCs, facilitating the exchange of information between cells to generate effective immune responses against endogenous and exogenous antigens (Ghislat and Lawrence, 2018).

\subsection{Viral hijacking and evasion of autophagy}

The life cycle of a virus generally includes the processes of virus adsorption and invasion, intracellular replication, transcription and translation, assembly, and release (Duan et al., 2020). In the case of cellular autophagy, viruses hijack the autophagy machinery throughout their life cycle to survive within the cell, and express specific proteins to escape autophagy and multiply within the host cell (Ahmad et al., 2018).

The key problem of coronaviruses using autophagy to promote their own replication lies in determining whether the replication of the virus requires the assistance of autophagy, as illustrated by studies of mouse hepatitis virus (MHV). In mouse Atg5 knockout embryonic stem cells (ESCs), Prentice et al. (2004a) found that both MHV replication and double-membrane vesicle (DMV) formation were impaired and that viral reverse transcription complexes (RTCs) co-localized with endogenous LC3. This suggests that autophagy occurrence and DMV formation are associated with
MHV replication. Similarly, the same group observed co-localization of viral RTCs with endogenous LC3 in another severe acute respiratory syndrome coronavirus 2 (SARS-CoV-2)-related study (Prentice et al., 2004b). However, this conclusion has been disputed by Zhao et al. (2007), who also observed co-localization of viral RTCs with endogenous LC3, but did not find any effect on the MHV life cycle in bone marrow macrophages (BMMs) or mouse embryonic fibroblasts (MEFs) deficient in Atg5. In contrast, Snijder et al. (2006) failed to detect co-localization of LC3 or green fluorescent protein (GFP)-LC3 with viral RTCs of SARS-CoV in SARS-CoV-infected African green monkey kidney (Vero) cells. A related study showed that knockdown of Atg5 did not affect SARS-CoV replication (Schneider et al., 2012). Contradictory results were also seen in studies of infectious bronchitis virus (IBV). On the one hand, it has been shown that IBV-induced autophagy is dependent on ATG5, and that the endoplasmic reticulum stress sensor inositol-requiring enzyme 1 (IRE1) and mitogen activated protein (MAP) kinase ERK1/2 are required for IBV-induced autophagy and play a survival-promoting role in the late stages of IBV infection (Fung and Liu, 2019). On the other hand, Maier et al. (2013) found that although overexpression of IBV's nonstructural protein 6 (NSP6) induced autophagic signaling, induction or inhibition of autophagy did not affect IBV replication, suggesting that classical autophagy might not be important for viral replication. Thus, there is no definitive answer as to whether autophagy is required for coronavirus replication. However, results so far suggest that the effect of autophagy on coronavirus might vary considerably depending on the origin of the cells, as several of the above studies used cells sourced from different tissues of the same species or of different species. In addition, these results suggest that the "need" for autophagy might not be the same in different cells, and that in addition to ATG5, important autophagy proteins, such as LC3 and Beclin1, might play an important role in viral replication. Furthermore, whether coronaviruses can use autophagy to promote their own replication, or whether induced autophagy can enhance viral proliferation, is unclear. Some studies have provided positive evidence. Guo et al. (2017) found that in Vero cells, porcine epidemic disease virus (PEDV) was able to induce autophagy to promote its own replication. Also, reduced production of infectious viral particles 
was found in cells deficient in Beclin1 or ATG5 or in cells treated with 3-methyladenine, suggesting that autophagy induced during PEDV infection was beneficial to the virus. Zhu et al. (2016) found that the transmissible gastroenteritis coronavirus (TGEV) nucleocapsid protein (N) and GFP-LC3 were localized to mitochondria. The induction of mitochondrial autophagy using carbonyl cyanide 3-chlorophenylhydrazone (CCCP) depolarized mitochondria and increased viral titers, suggesting that this pathway might facilitate viral replication. Human coronavirus (HCoV)-OC43 infection increased autophagic flux in human lung fibroblast MRC-5 cells. Treatment of the cells with kurarinone reduced virus-induced autophagic flux and thus inhibited viral replication (Min et al., 2020). These results suggest that autophagy can be beneficial for coronaviruses, promoting their proliferation by enhancing the autophagic pathway. Conversely, disruption of the autophagic pathway can reduce viral replication. Notably, coronaviruses might also hijack a component of autophagy for the purpose of aiding or facilitating replication, and this activity is not dependent on the classical autophagic pathway. For example, it has been found that although the autophagic pathway is not essential for MHV infection, the non-lipidated form of LC3-I is closely associated with coronavirusinduced DMV and is required for MHV replication (Reggiori et al., 2010).

Middle East respiratory syndrome-coronavirus (MERS-CoV) is able to reduce Beclin1 activity by activating S-phase kinase-associated protein 2 (SKP2), which inhibits the fusion of autophagosomes with lysosomes, thereby blocking the destructive effects of autophagy on the virus (Gassen et al., 2019). The membrane-associated papain-like protease 2 (PLP2$\mathrm{TM}$ ) of various coronaviruses induces incomplete autophagy and inhibits the natural immune response by interacting with Beclin1 and promoting the interaction between Beclin1 and STING. Knockdown of Beclin1 partially reverses the inhibitory effect of PLP2-TM, leading to a reduction in viral replication (Chen XJ et al., 2014). From these results, it is clear that coronaviruses have diverse strategies to resist autophagy. The structural similarities between the coronavirus replication site DMV and autophagosomes allow some coronaviruses to induce the production of autophagosomes to assist their own proliferation. In addition, to avoid damage to the virus by autophagic degradation, coronaviruses often block subsequent steps of the autophagic pathway, such as preventing the expansion of autophagosomes or blocking the fusion between autophagosomes and lysosomes. Autophagy is also involved in the body's immune response (Channappanavar et al., 2014). Therefore, coronaviruses can also escape from natural immune "supervision" by inducing autophagy, allowing some autophagic proteins to interact with relevant immune signaling pathways, thereby inhibiting the IFN signaling pathway.

\section{Fungi and cellular autophagy}

\subsection{Autophagy mechanism of Saccharomyces cerevisiae}

In the early 1990s, a group of cell biologists, represented by Daniel J. KLIONSKY and Yoshinori OHSUMI, started the screening and cell biology of autophagy-related genes using Saccharomyces cerevisiae as a model organism. To date, over 40 autophagyrelated genes have been identified in yeast ( $\mathrm{Yu}$ et al., 2020). More than two decades later, S. cerevisiae has become the most commonly used model organism in the study of the molecular mechanisms of cellular autophagy (Feng et al., 2014; Yin et al., 2019). The macro-autophagy occurring in $S$. cerevisiae is of significant interest. This process occurs at the PAS, where the phagophore/isolation membrane expands and grows into an autophagosome with a bilayer membrane structure by the regulation of related proteins. At the same time, the cytoplasmic matrix is encapsulated into the autophagosomal lumen. Subsequently, the outer membrane of the autophagosome fuses with the vesicle, and the inner membrane and contents are degraded by hydrolytic enzymes into small molecules, such as amino acids, which are reused by the cell to help it survive in adverse conditions (Yang et al., 2019). The whole process of cellular autophagy can be divided conceptually into the following aspects: (1) regulation of cellular autophagy, (2) formation of autophagosomes in the PAS, (3) fusion of autophagosomes with vesicles, and (4) degradation and recycling of inclusions (Levine and Klionsky, 2004) (Fig. 2).

Under physiological conditions, cellular autophagy is tightly regulated. Two main pathways are known to regulate autophagy: the TOR and PI3K pathways (Yin et al., 2019). In yeast, TOR has two homologs, Tor1 
(a)

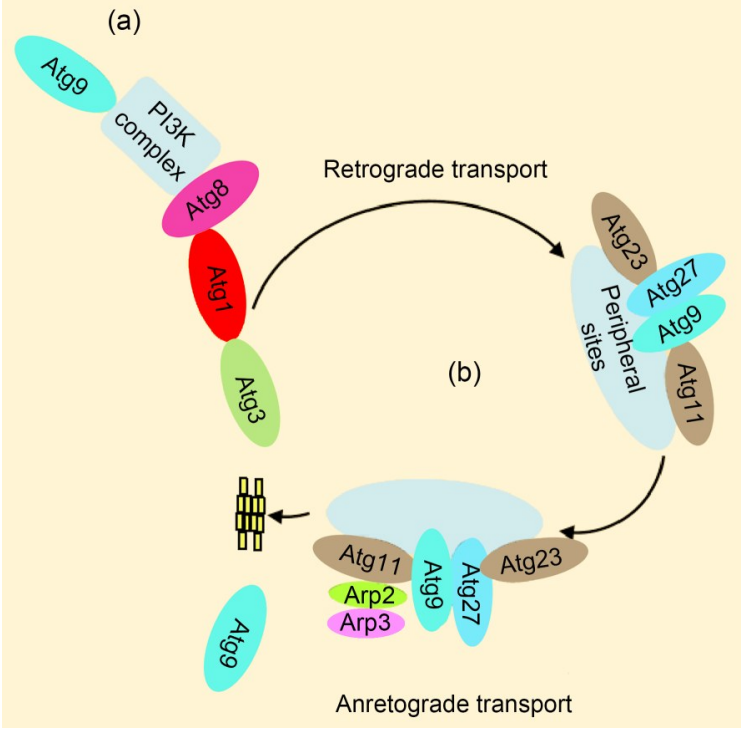

Fig. 2 Regulation of cellular autophagy by the PI3K complex and Atg9 in Saccharomyces cerevisiae. (a) PI3K signaling system. PI3K complex targeting of the PAS produces PI3P to recruit downstream effector proteins. (b) Atg9 recycling system. Atg9 is shuttled and trafficked between the PAS and the degradation sites. Under energy-enriched conditions, cis-transport of Atg9 to the PAS is dependent on Atg1, Atg23, Atg27, actin, and the Arp2-Arp3 complex. Atg9 forms a complex with Atg23 and Atg27. Atg1 is responsible for uploading the Atg9-Atg23-Atg27 complex to the PAS. The complex movement is facilitated by the Arp2-Arp3 complex. The anterograde transport of Atg9 under starvation conditions is dependent on Atg17 (not shown). The retrieval transport of Atg9 requires the synergistic action of the Atgl-Atgl3 complex, Atg2-Atg18 complex, and PI3K complex. PI3K: phosphatidylinositol 3-kinase; Atg: autophagy related; PAS: pre-autophagosome structure; PI3P: phosphatidylinositol 3-phosphate; Arp: actin-related protein.

and Tor2, which can form two protein complexes, TORC1 (containing either Tor1 or Tor2) and TORC2 (containing only Tor2) (Raught et al., 2001). Both complexes are involved in the regulation of cell growth and intracellular metabolism, but TORC1 is more sensitive to rapamycin (Loewith et al., 2002). In addition, TORC1 can sense extracellular nutrient conditions. When cells are in starvation conditions, TORC1 is inhibited and the level of cellular autophagy increases, thus being the main regulator of cellular autophagy (Yorimitsu and Klionsky, 2005; González and Hall, 2017).

In cellular autophagy, the formation of autophagosomes is a key step, and the size and number of autophagosomes also reflect the level of cellular autophagy. Here, we focus on the core systems involved in this step, including the assembly of the backbone of the PAS, the PI3K signaling system, and the Atg9 recycling system (Li et al., 2020).

\subsubsection{Assembly of the PAS backbone}

The PAS is the site of autophagosome formation, and is usually found close to the vesicles. Under fluorescence microscopy, most Atg proteins can be seen to co-localize to the PAS. So far, localization of the PAS appears to be a yeast-specific phenomenon, because the sites of autophagosome production in other species are spread throughout the cytoplasm, rather than being confined to a few sites (Cheng et al., 2014). It is generally believed that the assembly of Atg proteins in the PAS initiates from several important backbone proteins, and the specific process depends on the conditions of regulatory induction of cellular autophagy. In the Cvt pathway, which occurs under eutrophic growth conditions, the PAS assembly signal is derived from the Cvt complex transport. The main components of the Cvt complex are precursor Ape1 multimer and its receptor Atg19 (Scott et al., 2001; Yamasaki et al., 2016). Atg19 binds to Atg11, which then recruits other related proteins and gradually forms specialized autophagosome-Cvt vesicles around the Cvt complex. In this process, Atg11 plays the role of an assembly protein in PAS formation (Zientara-Rytter and Subramani, 2020). By contrast, Atg17 plays a major role when cells are under starvation conditions and nonselective autophagy is significantly enhanced (Matscheko et al., 2019). Atg17 is also involved in various aspects of autophagosome formation, including the regulation of Atg1 activity and the transport of Atg9 to the PAS (Kamada et al., 2000; Sekito et al., 2009) (Fig. 2b).

\subsubsection{PI3K complex signaling system}

PI3K is an important class of intracellular signaling regulatory molecules that control physiological processes, such as cell growth, differentiation, and transport of intracellular substances, through phosphorylation modification of phosphatidylinositol on the membrane. Class III PI3K is the oldest class and phosphorylates phosphatidylinositol to phosphatidylinositol 3-phosphate (PI3P). The yeast genome contains only one gene encoding PI3K, namely type III PI3K-Vps34 (Jaber and Zong, 2013). Vps34 is involved in the formation of at least two types of complexes. Class I complexes contain Atg14 and are involved in cellular 
autophagy. Class II complexes contain Vps38 and are involved in the vacuolar protein sorting (VPS) pathway, which is responsible for the translocation of proteins to vesicles via the Golgi apparatus (Kihara et al., 2001). Both complexes contain Vps34, Vps15, and Vps30/ Atg6 (Kihara et al., 2001). Vps15 is a protein kinase that forms the regulatory subunit of Vps34. Atg14 links Vps30/Atg6 to Vps34-Vps15 to form a complex. The coiled-coil domain (CCD) at the N-terminus of Atg14 executes this function (Matsunaga et al., 2010). In cellular autophagy, Atg14 localizes the PI3K complex to the PAS site and recruits downstream proteins through the PI3P product of the later (Matsunaga et al., 2010; Obara and Ohsumi, 2011; Harada et al., 2019) (Fig. 2a).

\subsubsection{Cyclic transport of Atg9}

Atg9 is the only transmembrane protein of the core autophagy machinery and might be the key to the origin of autophagosomal membranes (Yamamoto et al., 2012; Kirkin and Rogov, 2019). Atg9 is an integral membrane protein containing six highly conserved transmembrane domains as well as N-terminal and Cterminal domains located in the cytoplasm (Guardia et al., 2020). It participates in the formation of autophagosomes by cycling between the PAS and peripheral structures (e.g., mitochondria, endoplasmic reticulum, and Golgi apparatus) with the assistance of related proteins. Thus, Atg9 is considered to be a "membrane carrier" for vesicle formation (He et al., 2006). In yeast, the majority of Atg9 is located on the surface of mitochondrial membranes or on components attached to mitochondria (Reggiori et al., 2005b) (Fig. 2).

The transport of Atg9 from peripheral structures to the PAS is accomplished with the assistance of other proteins, and different assisting proteins are required under different conditions. In the selective cellular autophagic Cvt pathway, the transport of Atg9 from peripheral structures to the PAS is blocked when any of the components of Atg11, the Cvt complex, or the actin cytoskeleton are missing (Shintani and Klionsky, 2004a; Reggiori et al., 2005a; He et al., 2006). The actinrelated protein Arp2 interacts with Atg9 and directly regulates the transport of Atg9 from peripheral structures to the PAS. As a subunit of the Arp2-Arp3 complex, Arp2 likely facilitates the movement of Atg9 and remodels the actin structure to facilitate Atg9 transport (Reggiori et al., 2005a). In starvation-induced non-selective cellular autophagy, this transport requires
Atg17 (Sekito et al., 2009). Atg17 helps Atg9 localize to the PAS and complete membrane assembly (Kawamata et al., 2008; Sekito et al., 2009). The Atg1-Atg13 complex and the PI3K complex I are required for retrograde transport of Atg9 from the PAS. However, this process does not require the kinase activity of Atg1 (Reggiori et al., 2004). The role of Atg1 in this process is most likely to regulate the balance between Atg9 assembly and retrieval at the PAS site (Reggiori et al., 2004). In addition, anterograde transport of Atg9 requires Atg23 and Atg27, which, like Atg9, are localized to the PAS and some other scattered membrane structures in the cytoplasm (Backues et al., 2015). During transport, the three are transferred together as a complex (Backues et al., 2015) (Fig. 2).

When the autophagosome is completed, Atg9 does not remain on the autophagosomal membrane, but returns from the PAS to peripheral structures in the cytoplasm. This retrograde transport relies on the Atg1-Atg13 complex (Reggiori et al., 2004), the Atg2Atg18 complex (Kotani et al., 2018), and the Vps34 complex I (Reggiori et al., 2004). One widely accepted model is that once the Atg1-Atg13 complex is recruited to the Atg9-located PAS, Atg1-Atg13 drives Atg9 to interact with Atg2-Atg18 and the subsequent formation of a large multiprotein complex drives Atg9 from the PAS back to the peripheral structures (Fig. 2).

\subsection{Fungal infection of host cells triggers autophagy}

In phagocytic cells, PRR- or Fc- $\gamma$ receptors (Fc $\gamma \mathrm{R})$ mediated phagocytosis-related autophagy-related molecules, such as LC3, Beclin1, PI3KC3, and ATG12ATG5 complexes, can decorate on the phagosome membrane, promoting phagosome fusion with lysosomes and the formation of a monolayer membrane structure. However, this process does not induce cell autophagy and is defined as LAP (Schille et al., 2018; Heckmann and Green, 2019). The occurrence of LAP is independent of the induction of the ULK1 complex (Martinez et al., 2011). Rubicon and NOX2 act on class III PI3K complexes and promote phagocytosis with the participation of the ATG16L complex (Martinez et al., 2015). The formation of LAP can promote the presentation of fungal antigens by MHC-II molecules (Ma et al., 2012). In addition, the occurrence of LAP requires the productions of NADPH oxidase and ROS (Heckmann et al., 2017). How ROS induces the recruitment of LC3 to the phagosome surface and 
why autophagy-related molecules are involved in the aggregation of phagosomes and lysosomes remain unclear (Pauwels et al., 2017). However, it is certain that LAP plays an important role in controlling pathogen infections (Upadhyay and Philips, 2019). LAP also participates in the process of promoting phagocyte maturation. These findings link two conserved biological behaviors, autophagy and phagocytosis, to a synergistic mechanism that promotes the elimination of fungal pathogens.

When yeast cells invade an organism, they can form a vacuole that is not recognized by the host's lysosome. The vacuole acts as a barrier to protect the yeast cells from lysosomal action. However, when yeast cells invade macrophages that are activated by IFN- $\gamma$, the vacuolar membrane of yeast is disrupted, and the bare yeast cells are wrapped in autophagic vesicles, which are sent to the lysosome for degradation via autophagy, so as to clear the yeast cells from the organism. However, autophagy is not always good for the host, and might also be a necessary condition for the growth and infection of certain fungi. Studies have found that the Magnaporthe oryzae genome encodes Atg proteins that have been classified into four major groups, namely an Atg1-Atg13-Atg17 complex, an Atg9 trafficking system, a PI3K complex, and two Ub-like conjugation systems (Zhu et al., 2019). MoAtg2-MoAtg10, MoAtg12, MoAtg14-MoAtg16, and MoAtg18 have been shown to play an important role in M. oryzae-induced cell autophagy (Dong et al., 2009; Liu et al., 2010, 2012, 2017; Zhu et al., 2019; $\mathrm{Li}$ et al., 2021). Host cell autophagy can provide nourishment for the development and infection of M. oryzae by degrading organelles and senescent proteins. Therefore, autophagy plays an important role in the whole development and infection cycle of $M$. oryzae (Liu and Lin, 2008).

Furthermore, studies have shown that IFN- $\gamma$ activates autophagy in human macrophages, leading to an increase in anti-fungal host defense against $M$. oryzae infection. Other studies have reported that activation of macro-autophagy can promote phagosomal acidification and anti-fungal responses in murine and human macrophages, suggesting that autophagy might represent a promising host-targeting therapeutic strategy against $M$. oryzae infection.

Macrophages are an important population of cells involved in mediating the innate immunity of the host. Phagocytosis is the most important characteristic of macrophages, and plays an important role in killing and clearing fungal pathogens, as well as initiating and interaction with host cell autophagy (Ma and Underhill, 2013; $\mathrm{Wu}$ and $\mathrm{Lu}, 2019$ ). The occurrence of autophagy depends on autophagy-related receptors on the cell surface, mainly PRRs, Fc $\gamma$ Rs, complement receptors (CRs), such as C-type lectin receptors (like Dectin-1), mannose receptors (MRs), and TLRs (Öhman et al., 2014). The receptors bind to the corresponding ligand and activate autophagy-related proteins, thereby mediating cell autophagy. Dectin-1 receptor-mediated autophagy is an important part of the host's defense against fungal infection (Öhman et al., 2014; Kanayama and Shinohara, 2016; Tang et al., 2018). The recognition of fungal $\beta$-glucan by its receptor Dectin-1 triggers downstream signaling via spleen tyrosine kinase (SyK)dependent and Raf-1-dependent pathways to mediate antifungal immunity, including CARD-containing protein 9 (CARD9)-BCL-10-mucosa-associated translocation lymphoma 1 (MALT1) signaling (Ruland and Hartjes, 2019) and Raf-1 signaling pathways (Tang et al., 2018), which mediate the host's innate immune response to fungi (Salazar and Brown, 2018). The immune response can induce cell autophagy by producing ROS and secreting pro-inflammatory factors.

Studies have found that the Dectin-1/Syk pathway mediates the occurrence of autophagy via ROS production, LC3-lipidation, and so on (Ma et al., 2012; Kyrmizi et al., 2013; Tam et al., 2014), which plays an important role in resisting fungal infection (Smeekens et al., 2014; Kanayama et al., 2015). Candida albicans is one of the most common pathogenic Candida (Duhring et al., 2015). After infection, it can be swallowed into the cell by phagocytes (mainly macrophages and neutrophils) to induce an inflammatory response and affect the biological function of host cells (Miramón et al., 2012; Rudkin et al., 2013). The cell wall component, $\beta-1,3$-glucan, of $C$. albicans is considered to be a major PAMP and can be recognized by the Dectin-1 receptor (Bain et al., 2014). Because of the dysfunction of the autophagy process in mice with Atg5 knockout in vaginal cells, the secretion of antiC. albicans cytokines was significantly reduced, as was the recruitment of neutrophils, ultimately leading to a decreased ability to clear C. albicans (Shroff et al., 2018). However, mice with Atg5 selectively knocked out in myeloid cells showed increased susceptibility 
and decreased survival (Nicola et al., 2012). Accumulating evidence showed that fungal microorganisms have evolved various ways to avoid the influence of autophagy, including blocking the signal pathway of autophagy, disturbing organelles, blocking the fusion of autophagosomes and lysosomes, and even using autophagy to evade recognition and relying on autophagosomes to survive in the cell for a long time.

\section{Parasites and autophagy}

\subsection{Autophagy eliminates parasites}

Parasites are an important class of pathogens. The worms stimulate host cells to maintain a balance between inducing and evading the host immune response, and host cells also maintain a balance between infection and elimination.

Research on the interaction between autophagy and parasitic infections has focused mostly on serious intracellular parasitic protozoa, such as Toxoplasma gondii (Attias et al., 2020). The protozoa of the $T$. gondii class comprise a group of parasites that cause serious infections, and their process of invasion of host cells includes adhesion, invasion, and the formation of parasitophorous vacuoles (Portes et al., 2020). Such parasites can prevent the killing effect of lysosomes because of the protective effect of parasitophorous vacuoles, thus creating an autophagy evasion effect (Coppens et al., 2006). As a part of natural immunity, when foreign parasites enter the body, autophagy can encapsulate the invading parasites, mainly through PRRs in the cytoplasm and on membranes to sense the invading pathogens, thereby triggering innate immune signaling to form the first defense barrier (Sasai and Yamamoto, 2019). In this process, TLR4 initiates recognition, activates MyD88- and TRIF-dependent signaling pathways, and initiates the activation of the inhibitor of NF- $\mathrm{NB}$ kinase $\alpha(\mathrm{IKK} \alpha)$-IKK $\beta$-NF- $\mathrm{KB}$ essential modulator (NEMO) complex and the IKKi complex to regulate nuclear transcription factors NF- $\mathrm{\kappa B}$ and IRF3. These in turn induce the transcription of inflammatory factors and type I IFNs, thereby activating the IFN-mediated cellular anti-pathogen response (Zare-Bidaki et al., 2014). Research has also revealed that in the RAW macrophage cell line, TLR2 signaling triggers the autophagosome marker LC3 to be rapidly recruited to the phagosome, which then fuses with lysosomes to destruct and digest engulfed organisms (Sanjuan et al., 2007).

Type II IFN (IFN- $\gamma$ ) promotes autophagy by inducing GTPases to participate in autophagy formation. T. gondii enters host cells to form parasitophorous vacuoles, which have no receptors that can be recognized and captured by lysosomes. Thus, they can successfully escape lysosome-mediated phagocytosis (Fig. 3). T. gondii infection of activated macrophages induces the expression of the autophagy-related molecule ATG5, and then recruits IFN- $\gamma$ to induce p47 GTPase IIGP1 (also known as Irga6) to the parasitophorous vacuole membrane. Macrophage GTPases are activated to damage the parasitophorous vacuole (Zhao et al., 2008). The vacuole membrane is disrupted, the plasma membrane of the worm body is stripped, and autophagic vacuoles in the cell then wrap the naked parasite, which is subsequently transported to the lysosome for degradation of the worm body (Zhao et al., 2008). Conversely, if autophagy is inhibited by regulating the PI3K signaling pathway, the ability of host cells to degrade $T$. gondii will be impaired, indicating that autophagy is necessary for the degradation of T. gondii (Subauste, 2019). One group studied a culture of $T$. gondii tachyzoites in skeletal muscle cells (SkMCs) and found that after increasing the level of SkMC autophagy, ultrastructural observations showed that many autophagosome-like structures were distributed near the parasitophorous vacuole membrane of the worm, which contains parts of the parasites to be degraded. This suggests that an increase in the level of SkMC autophagy has a certain clearance effect on the infection and development of $T$. gondii tachyzoites. Besides the participation of ATG5, Ohshima et al. (2014) found that human ATG16L1 and mouse Atg7 and Atg16L1 are involved in the recruitment reaction mediated by IFN- $\gamma$ to complete the elimination of $T$. gondii. In addition to its important role in natural immunity, autophagy regulates the body's adaptive immune response and plays an important role by participating in antigen processing and presentation of MHC molecules (Fig. 3). Different groups found that during autophagic killing of T. gondii, IFN- $\gamma$ stimulates astrocytes and macrophages to recruit to $\mathrm{p} 47$ GTPases to the parasitophorous vacuole, disintegrating the parasite into fragments (Halonen et al., 2001; Martens et al., 2005; Ling et al., 2006; Melzer et al., 2008). Autophagy then regulates the antigen presentation 
pathway of MHC class II molecules and transports the worm antigens from the cytoplasm to the lysosome to complete phagocytosis and removal of the worm debris. When cellular autophagy is inhibited or interfered with, the ability to eliminate parasites is significantly reduced (Subauste, 2019) (Fig. 3).

\subsection{Parasites use autophagy to help their own development}

In the long-term evolutionary process, some parasites have formed specific mechanisms to induce incomplete cell autophagy, and the recycled materials produced by autophagy provide favorable conditions for parasite replication and development, thereby achieving intracellular proliferation and growth (Salassa and Romano, 2019). Alvarez et al. (2008) showed that during the development cycle of Trypanosoma cruzi, the process of proliferation and differentiation from epimastigotes to the formation of trypanosomes requires many amino acids. Under nutrient deficiency conditions, T. cruzi can use TcAtg4 and TcAtg8 to induce host cells to degrade cytoplasm and organelles via the autophagy pathway to provide a source of nutrients for their own differentiation and development (Fig. 3). Although host cell autophagy plays a certain role in the elimination of $T$. gondii, it has been shown that $T$. cruzi can mediate the degree of host cell autophagy and provide biological energy for the development of the parasite by inducing host cell autophagy (Alvarez et al., 2008; Romano et al., 2009). In cells deficient in

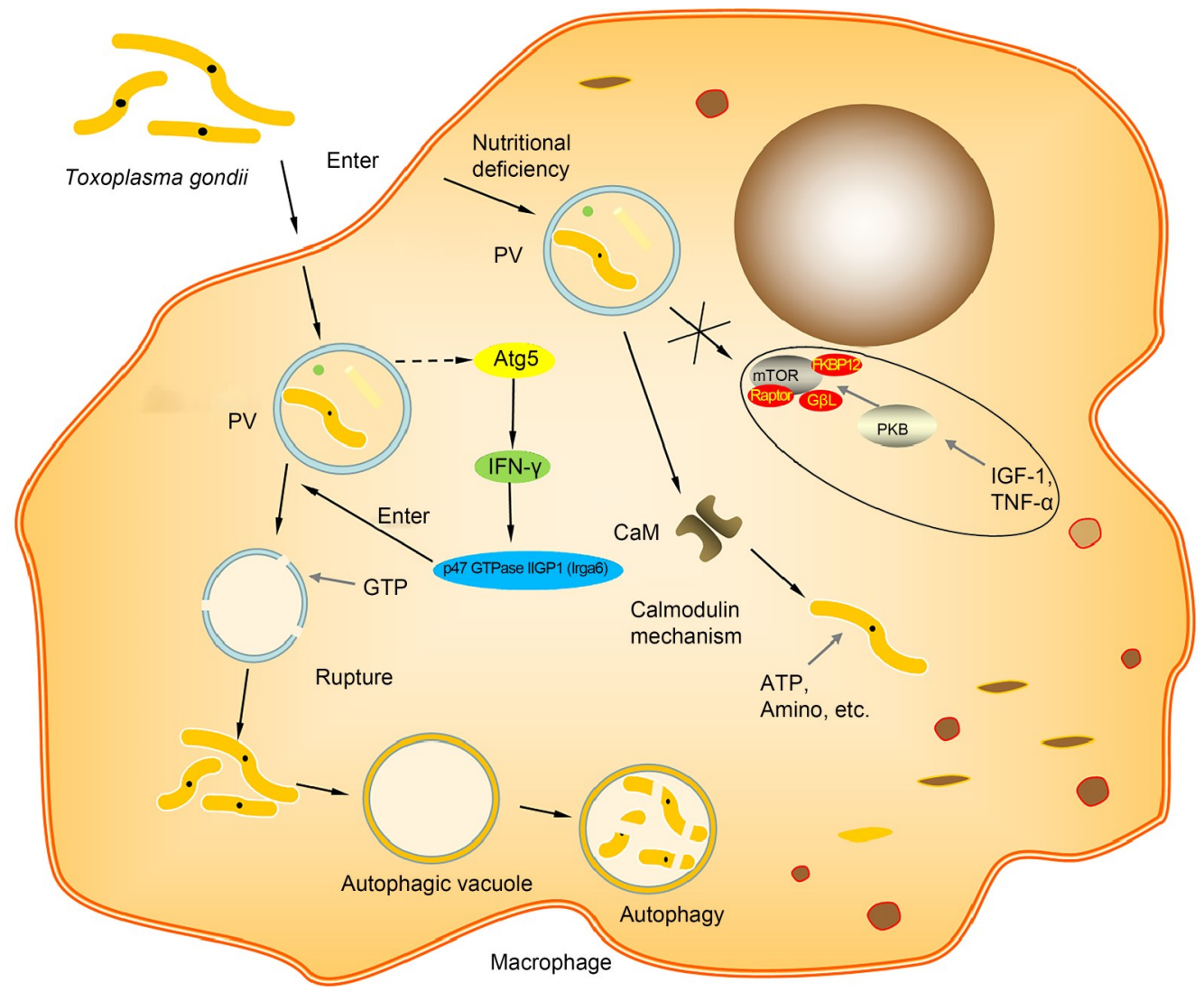

Fig. 3 Interaction between autophagy and parasites. After Toxoplasma gondii infects activated macrophages, the host cell ATG5 is induced, and then IFN- $\gamma$ is recruited to induce p47 GTPase IIGP1 into the vacuole membrane of Toxoplasma. The GTPases destroy the vacuole membrane of Toxoplasma, and the constitutive membrane of Toxoplasma is separated. The autophagic vacuole in the host cell then encapsulates the exposed parasite, and transports it to the lysosome for degradation. In the absence of nutritional conditions, the worm is not controlled by the traditional mTOR pathway, but depends on nutrients obtained by autophagic degradation of host cells to provide energy for its own development via calcium regulation. ATG5: autophagy-related 5; IFN: interferon; GTP: guanosine triphosphate; GTPase: guanosine triphosphatase; mTOR: mammalian target of rapamycin; ATP: adenosine triphosphate; CaM: calmodulin; FKBP12: FK506-binding protein 12; GßL: G protein $\beta$-subunit-like protein; PKB: protein kinase B; IGF-1: insulin-like growth factor-1; TNF- $\alpha$ : tumor necrosis factor- $\alpha$; PV: parasitophorous vacuole; CaM: calmodulin. 
ATG5, a crucial molecule of autophagy, the growth of $T$. gondii is markedly restricted (Wang et al., 2009). It was speculated that the reason for this is that the autophagy mediated by $T$. gondii is closely related to the accumulation of calcium. In the absence of nutritional conditions, Toxoplasma cannot be controlled by the traditional mTOR pathway, but competes with host cells for the material resources needed for anabolism via calcium regulation, and uses the nutrients obtained by the autophagic degradation of host cells to provide energy for Toxoplasma development (Wang et al., 2009) (Fig. 3).

Normally, the occurrence of calcium regulation events in infected cells is accompanied by high levels of PI3P, and Toxoplasma infection can independently regulate calcium signals. The restriction of PI3P distribution in the vicinity of the vacuole membrane of the worm is not necessary as it can be relocated with Beclin1 and LC3. This process is controlled by the worm. That is, T. gondii can control the location of host cell autophagy in a purposeful manner, instead of extensively and blindly inducing host cell autophagy. This, to some extent, enhances the ability of the parasite to capture and use host cell biological energy. Gao et al. (2014) found that the invasion of $T$. gondii tachyzoites can cause human embryonic fibroblasts (HEFs) to produce significant amounts of autophagy. When the autophagy inhibitors chloroquine and bafilomycin were used to treat HEF cells, the invasion rate of $T$. gondii was lower than that of the untreated control group. The results indicated that invasion of host cells by $T$. gondii promotes its own proliferation and development by causing an increase in the level of host cell autophagy.

Based on current findings, there are two recognized outcomes of cellular autophagy and intracellular parasite interactions during parasite infection of host cells. One is that autophagy successfully reduces the parasite invasion rate, and the other is that the parasite uses the formation of autophagic vesicles to provide substrates for its own energy metabolism, thus promoting its own reproductive development (GharteyKwansah et al., 2020a, 2020b).

\section{Conclusions}

Autophagy is an automatic cellular defense system that can actively respond to the invasion of pathogenic microbes, such as bacteria, viruses, fungi, and parasites, by directly removing them or modulating innate adaptive immune responses to destroy them. At the same time, when cellular autophagy is triggered, pathogens can also escape or use autophagy to promote their own survival. The regulatory role of autophagy in pathogen infections has several characteristics. First, there is a dual regulatory role between microbial pathogens and the body's defenses against infections. Second, the effect of autophagy depends on the cell type, pathogen characteristics, and the microenvironment in which pathogens are located.

Therefore, in order to treat infectious diseases, autophagy should be induced or inhibited in a reasonable manner to play an appropriate role, considering the characteristics of pathogenic microorganisms and their infections, to achieve the goal of inhibiting pathogen infections without damaging the organism. At the same time, regulating autophagy to keep the organism in a good metabolic state might be an effective strategy to proactively prevent pathogenic infections. Notably, deletion of different autophagy-related genes sometimes produces different symptomatic manifestations. In conclusion, much work is still needed to explore the dynamic regulatory roles of autophagy in pathogen infections, and the fine tuning of these mechanisms could provide a new theoretical basis and clinical drug targets for novel antimicrobial and anti-infective research.

\section{Acknowledgments}

This work was supported by the National Natural Science Foundation of China (Nos. 81871312 and 81701546) and the Natural Science Foundation of Henan Province (No. 182300410327). We would like to apologize to those researchers whose related work was not cited in this review. We would like to thank Yichuan XIAO (Chinese Academy of Sciences, Shanghai, China) and Tonglei SHI (Nankai University, Tianjin, China) for helpful comments and discussions on the manuscript.

\section{Author contributions}

Liangwei DUAN and Hui WANG conceived and designed the review. Qianqian ZHENG and Liangwei DUAN drafted the manuscript. Yang ZHANG, Jiaoyang LI, and Shiyu ZHANG prepared the figures. Liangwei DUAN and Hui WANG revised the manuscript. All authors have read and approved the final manuscript.

\section{Compliance with ethics guidelines}

Qianqian ZHENG, Liangwei DUAN, Yang ZHANG, Jiaoyang LI, Shiyu ZHANG, and Hui WANG declare that 
they have no conflict of interest.

This article does not contain any studies with human or animal subjects performed by any of the authors.

\section{References}

Abdoli A, Alirezaei M, Mehrbod P, et al., 2018. Autophagy: the multi-purpose bridge in viral infections and host cells. Rev Med Virol, 28(4):e1973. https://doi.org/10.1002/rmv.1973

Ahmad L, Mostowy S, Sancho-Shimizu V, 2018. Autophagyvirus interplay: from cell biology to human disease. Front Cell Dev Biol, 6:155. https://doi.org/10.3389/fcell.2018.00155

Allen EA, Amato C, Fortier TM, et al., 2020. A conserved myotubularin-related phosphatase regulates autophagy by maintaining autophagic flux. J Cell Biol, 219(11):e201909073. https://doi.org/10.1083/jcb.201909073

Alvarez VE, Kosec G, Sant'Anna C, et al., 2008. Autophagy is involved in nutritional stress response and differentiation in Trypanosoma cruzi. J Biol Chem, 283(6):3454-3464. https://doi.org/10.1074/jbc.M708474200

Anand PK, Tait SWG, Lamkanfi M, et al., 2011. TLR2 and RIP2 pathways mediate autophagy of Listeria monocytogenes via extracellular signal-regulated kinase (ERK) activation. J Biol Chem, 286(50):42981-42991. https://doi.org/10.1074/jbc.M111.310599

Andriantsitohaina R, Papon N, 2020. Extracellular vesicles: new bullets to fight fungal infections. Trends Cell Biol, 30(8):589-590. https://doi.org/10.1016/j.tcb.2020.05.008

Arasaki K, Mikami Y, Shames SR, et al., 2017. Legionella effector Lpg1137 shuts down ER-mitochondria communication through cleavage of syntaxin 17. Nat Commun, 8:15406. https://doi.org/10.1038/ncomms15406

Attias M, Teixeira DE, Benchimol M, et al., 2020. The lifecycle of Toxoplasma gondii reviewed using animations. Parasit Vectors, 13:588. https://doi.org/10.1186/s13071-020-04445-z

Backues SK, Orban DP, Bernard A, et al., 2015. Atg23 and Atg27 act at the early stages of Atg9 trafficking in $S$. cerevisiae. Traffic, 16(2):172-190. https://doi.org/10.1111/tra.12240

Bah A, Vergne I, 2017. Macrophage autophagy and bacterial infections. Front Immunol, 8:1483. https://doi.org/10.3389/fimmu.2017.01483

Bain JM, Louw J, Lewis LE, et al., 2014. Candida albicans hypha formation and mannan masking of $\beta$-glucan inhibit macrophage phagosome maturation. mBio, 5(6):e01874-14. https://doi.org/10.1128/mBio.01874-14

Barnett TC, Liebl D, Seymour LM, et al., 2013. The globally disseminated M1T1 clone of group A Streptococcus evades autophagy for intracellular replication. Cell Host Microbe, 14(6):675-682. https://doi.org/10.1016/j.chom.2013.11.003

Bauckman KA, Owusu-Boaitey N, Mysorekar IU, 2015. Selective autophagy: xenophagy. Methods, 75:120-127. https://doi.org/10.1016/j.ymeth.2014.12.005

Birmingham CL, Smith AC, Bakowski MA, et al., 2006. Autophagy controls Salmonella infection in response to damage to the Salmonella-containing vacuole. $J$ Biol Chem, 281(16):11374-11383. https://doi.org/10.1074/jbc.M509157200

Birmingham CL, Canadien V, Gouin E, et al., 2007. Listeria monocytogenes evades killing by autophagy during colonization of host cells. Autophagy, 3(5):442-451. https://doi.org/10.4161/auto. 4450

Cadwell K, 2016. Crosstalk between autophagy and inflammatory signalling pathways: balancing defence and homeostasis. Nat Rev Immunol, 16(11):661-675. https://doi.org/10.1038/nri.2016.100

Cardenal-Muñoz E, Arafah S, López-Jiménez AT, et al., 2017. Mycobacterium marinum antagonistically induces an autophagic response while repressing the autophagic flux in a TORC1- and ESX-1-dependent manner. PLoS Pathog, 13(4):e1006344. https://doi.org/10.1371/journal.ppat.1006344

Chang TK, Shravage BV, Hayes SD, et al., 2013. Ubal functions in Atg7- and Atg3-independent autophagy. Nat Cell Biol, 15(9):1067-1078. https://doi.org/10.1038/ncb2804

Channappanavar R, Zhao JC, Perlman S, 2014. T cellmediated immune response to respiratory coronaviruses. Immunol Res, 59:118-128. https://doi.org/10.1007/s12026-014-8534-Z

Chen G, Han Z, Feng D, et al., 2014. A regulatory signaling loop comprising the PGAM5 phosphatase and CK2 controls receptor-mediated mitophagy. Mol Cell, 54(3):362-377. https://doi.org/10.1016/j.molcel.2014.02.034

Chen XJ, Wang K, Xing YL, et al., 2014. Coronavirus membrane-associated papain-like proteases induce autophagy through interacting with Beclin1 to negatively regulate antiviral innate immunity. Protein Cell, 5(12):912-927. https://doi.org/10.1007/s13238-014-0104-6

Cheng JL, Fujita A, Yamamoto H, et al., 2014. Yeast and mammalian autophagosomes exhibit distinct phosphatidylinositol 3-phosphate asymmetries. Nat Commun, 5:3207. https://doi.org/10.1038/ncomms4207

Cheng MI, Chen C, Engström P, et al., 2018. Actin-based motility allows Listeria monocytogenes to avoid autophagy in the macrophage cytosol. Cell Microbiol, 20(9):e12854. https://doi.org/10.1111/cmi.12854

Cheng YL, Kuo CF, Lu SL, et al., 2019. Group A streptococcus induces LAPosomes via $\mathrm{SLO} / \beta 1$ integrin/NOX2/ROS pathway in endothelial cells that are ineffective in bacterial killing and suppress xenophagy. mBio, 10(5):e02148-19. https://doi.org/10.1128/mBio.02148-19

Chew LH, Lu S, Liu X, et al., 2015. Molecular interactions of the Saccharomyces cerevisiae Atg1 complex provide insights into assembly and regulatory mechanisms. Autophagy, 11(6):891-905. https://doi.org/10.1080/15548627.2015.1040972

Choi Y, Bowman JW, Jung JU, 2018. Autophagy during viral infection - a double-edged sword. Nat Rev Microbiol, 16(6):341-354. 
https://doi.org/10.1038/s41579-018-0003-6

Choy A, Dancourt J, Mugo B, et al., 2012. The Legionella effector RavZ inhibits host autophagy through irreversible Atg8 deconjugation. Science, 338(6110):1072-1076. https://doi.org/10.1126/science.1227026

Chun Y, Kim J, 2018. Autophagy: an essential degradation program for cellular homeostasis and life. Cells, 7(12):278. https://doi.org/10.3390/cells7120278

Coppens I, 2017. How Toxoplasma and malaria parasites defy first, then exploit host autophagic and endocytic pathways for growth. Curr Opin Microbiol, 40:32-39. https://doi.org/10.1016/j.mib.2017.10.009

Coppens I, dan Dunn J, Romano JD, et al., 2006. Toxoplasma gondii sequesters lysosomes from mammalian hosts in the vacuolar space. Cell, 125(2):261-274. https://doi.org/10.1016/j.cell.2006.01.056

Coulon PG, Richetta C, Rouers A, et al., 2016. HIV-infected dendritic cells present endogenous MHC class II-restricted antigens to HIV-specific CD4 ${ }^{+}$T cells. J Immunol, 197(2): 517-532. https://doi.org/10.4049/jimmunol.1600286

Dai XF, Zhu ML, 2020. Coupling of ribosome synthesis and translational capacity with cell growth. Trends Biochem Sci, 45(8):681-692. https://doi.org/10.1016/j.tibs.2020.04.010

Deretic V, 2010. Autophagy in infection. Curr Opin Cell Biol, 22(2):252-262. https://doi.org/10.1016/j.ceb.2009.12.009

Deretic V, 2012. Autophagy as an innate immunity paradigm: expanding the scope and repertoire of pattern recognition receptors. Curr Opin Immunol, 24(1):21-31. https://doi.org/10.1016/j.coi.2011.10.006

Deretic V, Levine B, 2009. Autophagy, immunity, and microbial adaptations. Cell Host Microbe, 5(6):527-549. https://doi.org/10.1016/j.chom.2009.05.016

Desai M, Fang R, Sun JR, 2015. The role of autophagy in microbial infection and immunity. Immunotargets Ther, 4:13-26. https://doi.org/10.2147/ITT.S76720

Dong B, Liu XH, Lu JP, et al., 2009. MgAtg9 trafficking in Magnaporthe oryzae. Autophagy, 5(7):946-953. https://doi.org/10.4161/auto.5.7.9161

Dortet L, Mostowy S, Louaka AS, et al., 2011. Recruitment of the major vault protein by InlK: a Listeria monocytogenes strategy to avoid autophagy. PLoS Pathog, 7(8):e1002168. https://doi.org/10.1371/journal.ppat.1002168

Duan LW, Zheng QQ, Zhang HX, et al., 2020. The SARSCoV-2 spike glycoprotein biosynthesis, structure, function, and antigenicity: implications for the design of spikebased vaccine immunogens. Front Immunol, 11:576622. https://doi.org/10.3389/fimmu.2020.576622

Duhring S, Germerodt S, Skerka C, et al., 2015. Hostpathogen interactions between the human innate immune system and Candida albicans - understanding and modeling defense and evasion strategies. Front Microbiol, 6:625. https://doi.org/10.3389/fmicb.2015.00625

Ehlers MRW, 2000. CR3: a general purpose adhesionrecognition receptor essential for innate immunity. Microbes
Infect, 2(3):289-294.

https://doi.org/10.1016/s1286-4579(00)00299-9

Farag NS, Breitinger U, Breitinger HG, et al., 2020. Viroporins and inflammasomes: a key to understand virus-induced inflammation. Int J Biochem Cell Biol, 122:105738. https://doi.org/10.1016/j.biocel.2020.105738

Farré JC, Subramani S, 2016. Mechanistic insights into selective autophagy pathways: lessons from yeast. Nat Rev $\mathrm{Mol}$ Cell Biol, 17(9):537-552. https://doi.org/10.1038/nrm.2016.74

Feng YC, He D, Yao ZY, et al., 2014. The machinery of macroautophagy. Cell Res, 24(1):24-41. https://doi.org/10.1038/cr.2013.168

Fujioka Y, Alam JM, Noshiro D, et al., 2020. Phase separation organizes the site of autophagosome formation. Nature, 578(7794):301-305. https://doi.org/10.1038/s41586-020-1977-6

Fung TS, Liu DX, 2019. The ER stress sensor IRE1 and MAP kinase ERK modulate autophagy induction in cells infected with coronavirus infectious bronchitis virus. Virology, 533: 34-44. https://doi.org/10.1016/j.virol.2019.05.002

Gao DM, Zhang J, Zhao J, et al., 2014. Autophagy activated by Toxoplasma gondii infection in turn facilitates Toxoplasma gondii proliferation. Parasitol Res, 113(6): 2053-2058. https://doi.org/10.1007/s00436-014-3853-5

Gassen NC, Niemeyer D, Muth D, et al., 2019. SKP2 attenuates autophagy through Beclin1-ubiquitination and its inhibition reduces MERS-coronavirus infection. Nat Commun, 10:5770. https://doi.org/10.1038/s41467-019-13659-4

Ghartey-Kwansah G, Adu-Nti F, Aboagye B, et al., 2020a. Autophagy in the control and pathogenesis of parasitic infections. Cell Biosci, 10:101. https://doi.org/10.1186/s13578-020-00464-6

Ghartey-Kwansah G, Aboagye B, Adu-Nti F, et al., 2020b. Clearing or subverting the enemy: role of autophagy in protozoan infections. Life Sci, 247:117453. https://doi.org/10.1016/j.lfs.2020.117453

Ghislat G, Lawrence T, 2018. Autophagy in dendritic cells. Cell Mol Immunol, 15(11):944-952. https://doi.org/10.1038/cmi.2018.2

Glick D, Barth S, Macleod KF, 2010. Autophagy: cellular and molecular mechanisms. J Pathol, 221(1):3-12. https://doi.org/10.1002/path.2697

Gluschko A, Herb M, Wiegmann K, et al., 2018. The $\beta 2$ integrin Mac-1 induces protective LC3-associated phagocytosis of Listeria monocytogenes. Cell Host Microbe, 23(3): 324-337.e5. https://doi.org/10.1016/j.chom.2018.01.018

González A, Hall MN, 2017. Nutrient sensing and TOR signaling in yeast and mammals. EMBO J, 36(4):397-408. https://doi.org/10.15252/embj.201696010

Guardia CM, Tan XF, Lian TF, et al., 2020. Structure of human ATG9A, the only transmembrane protein of the core autophagy machinery. Cell Rep, 31(13):107837. https://doi.org/10.1016/j.celrep.2020.107837 
Gui X, Yang H, Li T, et al., 2019. Autophagy induction via STING trafficking is a primordial function of the cGAS pathway. Nature, 567(7747):262-266. https://doi.org/10.1038/s41586-019-1006-9

Guo XZ, Zhang MJ, Zhang XQ, et al., 2017. Porcine epidemic diarrhea virus induces autophagy to benefit its replication. Viruses, 9(3):53. https://doi.org/10.3390/v9030053

Halonen SK, Taylor GA, Weiss LM, 2001. Gamma interferoninduced inhibition of Toxoplasma gondii in astrocytes is mediated by IGTP. Infect Immun, 69(9):5573-5576. https://doi.org/10.1128/IAI.69.9.5573-5576.2001

Hamasaki M, Furuta N, Matsuda A, et al., 2013. Autophagosomes form at ER-mitochondria contact sites. Nature, 495(7441):389-393. https://doi.org/10.1038/nature11910

Harada K, Kotani T, Kirisako H, et al., 2019. Two distinct mechanisms target the autophagy-related E3 complex to the pre-autophagosomal structure. eLife, 8:e43088. https://doi.org/10.7554/eLife.43088

He CC, Song H, Yorimitsu T, et al., 2006. Recruitment of Atg9 to the preautophagosomal structure by $\operatorname{Atg} 11$ is essential for selective autophagy in budding yeast. J Cell Biol, 175(6):925-935. https://doi.org/10.1083/jcb.200606084

Heckmann BL, Green DR, 2019. LC3-associated phagocytosis at a glance. $J$ Cell Sci, 132(5):jcs222984. https://doi.org/10.1242/jcs.222984

Heckmann BL, Boada-Romero E, Cunha LD, et al., 2017. LC3-associated phagocytosis and inflammation. $J \mathrm{Mol}$ Biol, 429(23):3561-3576. https://doi.org/10.1016/j.jmb.2017.08.012

$\mathrm{Hu}$ W, Chan H, Lu L, et al., 2020. Autophagy in intracellular bacterial infection. Semin Cell Dev Biol, 101:41-50. https://doi.org/10.1016/j.semcdb.2019.07.014

Huett A, Heath RJ, Begun J, et al., 2012. The LRR and RING domain protein LRSAM1 is an E3 ligase crucial for ubiquitin-dependent autophagy of intracellular Salmonella typhimurium. Cell Host Microbe, 12(6):778-790. https://doi.org/10.1016/j.chom.2012.10.019

Huss A, Derks LAN, Heederik DJJ, et al., 2020. Green waste compost as potential reservoirs of Legionella in the Netherlands. Clin Microbiol Infec, 26(9):1259.e1-1259.e3. https://doi.org/10.1016/j.cmi.2020.05.018

Hytönen J, Haataja S, Gerlach D, et al., 2001. The SpeB virulence factor of Streptococcus pyogenes, a multifunctional secreted and cell surface molecule with strepadhesin, laminin-binding and cysteine protease activity. Mol Microbiol, 39(2):512-519. https://doi.org/10.1046/j.1365-2958.2001.02269.x

Itakura E, Kishi-Itakura C, Mizushima N, 2012. The hairpintype tail-anchored SNARE syntaxin 17 targets to autophagosomes for fusion with endosomes/lysosomes. Cell, 151(6):1256-1269. https://doi.org/10.1016/j.cell.2012.11.001

Jaber N, Zong WX, 2013. Class III PI3K Vps34: essential roles in autophagy, endocytosis, and heart and liver function. Ann N Y Acad Sci, 1280(1):48-51. https://doi.org/10.1111/nyas.12026

Jennings E, Thurston TLM, Holden DW, 2017. Salmonella SPI-2 type III secretion system effectors: molecular mechanisms and physiological consequences. Cell Host Microbe, 22(2):217-231. https://doi.org/10.1016/j.chom.2017.07.009

Joo JH, Dorsey FC, Joshi A, et al., 2011. Hsp90-Cdc37 chaperone complex regulates Ulk1- and Atg13-mediated mitophagy. Mol Cell, 43(4):572-585. https://doi.org/10.1016/j.molcel.2011.06.018

Kagan JC, Stein MP, Pypaert M, et al., 2004. Legionella subvert the functions of Rab1 and Sec22b to create a replicative organelle. J Exp Med, 199(9):1201-1211. https://doi.org/10.1084/jem.20031706

Kamada Y, Funakoshi T, Shintani T, et al., 2000. Tormediated induction of autophagy via an Apg1 protein kinase complex. J Cell Biol, 150(6):1507-1513. https://doi.org/10.1083/jcb.150.6.1507

Kamber RA, Shoemaker CJ, Denic V, 2015. Receptor-bound targets of selective autophagy use a scaffold protein to activate the Atg1 kinase. Mol Cell, 59(3):372-381. https://doi.org/10.1016/j.molcel.2015.06.009

Kanayama M, Shinohara ML, 2016. Roles of autophagy and autophagy-related proteins in antifungal immunity. Front Immunol, 7:47. https://doi.org/10.3389/fimmu.2016.00047

Kanayama M, Inoue M, Danzaki K, et al., 2015. Autophagy enhances $\mathrm{NF \kappa B}$ activity in specific tissue macrophages by sequestering A20 to boost antifungal immunity. Nat Commun, 6:5779. https://doi.org/10.1038/ncomms6779

Kandul NP, Zhang T, Hay BA, et al., 2016. Selective removal of deletion-bearing mitochondrial DNA in heteroplasmic Drosophila. Nat Commun, 7:13100. https://doi.org/10.1038/ncomms 13100

Kato M, Yang YS, Sutter BM, et al., 2019. Redox state controls phase separation of the yeast ataxin-2 protein via reversible oxidation of its methionine-rich lowcomplexity domain. Cell, 177(3):711-721.e8. https://doi.org/10.1016/j.cell.2019.02.044

Kaushik S, Cuervo AM, 2018. The coming of age of chaperone-mediated autophagy. Nat Rev Mol Cell Biol, 19(6):365-381. https://doi.org/10.1038/s41580-018-0001-6

Kawabata T, Yoshimori T, 2020. Autophagosome biogenesis and human health. Cell Discov, 6:33. https://doi.org/10.1038/s41421-020-0166-y

Kawamata T, Kamada Y, Kabeya Y, et al., 2008. Organization of the pre-autophagosomal structure responsible for autophagosome formation. Mol Biol Cell, 19(5):2039-2050. https://doi.org/10.1091/mbc.E07-10-1048

Keil E, Höcker R, Schuster M, et al., 2013. Phosphorylation of Atg 5 by the Gadd45 $\beta$-MEKK4-p38 pathway inhibits autophagy. Cell Death Differ, 20(2):321-332. https://doi.org/10.1038/cdd.2012.129

Kihara A, Noda T, Ishihara N, et al., 2001. Two distinct Vps34 phosphatidylinositol 3-kinase complexes function in autophagy and carboxypeptidase Y sorting in Saccharomyces 
cerevisiae. J Cell Biol, 152(3):519-530.

https://doi.org/10.1083/jcb.152.3.519

Kim J, Kundu M, Viollet B, et al., 2011. AMPK and mTOR regulate autophagy through direct phosphorylation of Ulk1. Nat Cell Biol, 13(2):132-141. https://doi.org/10.1038/ncb2152

Kim SI, Kim S, Kim E, et al., 2018. Secretion of Salmonella pathogenicity island 1-encoded type III secretion system effectors by outer membrane vesicles in Salmonella enterica serovar typhimurium. Front Microbiol, 9:2810. https://doi.org/10.3389/fmicb.2018.02810

Kimmey JM, Stallings CL, 2016. Bacterial pathogens versus autophagy: implications for therapeutic interventions. Trends Mol Med, 22(12):1060-1076. https://doi.org/10.1016/j.molmed.2016.10.008

Kirkin V, Rogov VV, 2019. A diversity of selective autophagy receptors determines the specificity of the autophagy pathway. Mol Cell, 76(2):268-285. https://doi.org/10.1016/j.molcel.2019.09.005

Kishi-Itakura C, Ktistakis NT, Buss F, 2020. Ultrastructural insights into pathogen clearance by autophagy. Traffic, 21(4):310-323. https://doi.org/10.1111/tra.12723

Kobayashi S, Koujin T, Kojidani T, et al., 2015. BAF is a cytosolic DNA sensor that leads to exogenous DNA avoiding autophagy. Proc Natl Acad Sci USA, 112(22):7027-7032. https://doi.org/10.1073/pnas.1501235112

Kocaturk NM, Gozuacik D, 2018. Crosstalk between mammalian autophagy and the ubiquitin-proteasome system. Front Cell Dev Biol, 6:128. https://doi.org/10.3389/fcell.2018.00128

Kotani T, Kirisako H, Koizumi M, et al., 2018. The Atg2-Atg18 complex tethers pre-autophagosomal membranes to the endoplasmic reticulum for autophagosome formation. Proc Natl Acad Sci USA, 115(41):10363-10368. https://doi.org/10.1073/pnas.1806727115

Kourtis N, Tavernarakis N, 2009. Autophagy and cell death in model organisms. Cell Death Differ, 16(1):21-30. https://doi.org/10.1038/cdd.2008.120

Kumsta C, Chang JT, Schmalz J, et al., 2017. Hormetic heat stress and HSF-1 induce autophagy to improve survival and proteostasis in C. elegans. Nat Commun, 8:14337. https://doi.org/10.1038/ncomms14337

Kyrmizi I, Gresnigt MS, Akoumianaki T, et al., 2013. Corticosteroids block autophagy protein recruitment in Aspergillus fumigatus phagosomes via targeting dectin-1/Syk kinase signaling. J Immunol, 191(3):1287-1299. https://doi.org/10.4049/jimmunol.1300132

Lecuit M, 2020. Listeria monocytogenes, a model in infection biology. Cell Microbiol, 22(4):e13186. https://doi.org/10.1111/cmi.13186

Lee YK, Lee JA, 2016. Role of the mammalian ATG8/LC3 family in autophagy: differential and compensatory roles in the spatiotemporal regulation of autophagy. BMB Rep, 49(8):424-430. https://doi.org/10.5483/bmbrep.2016.49.8.081

Levine B, 2005. Eating oneself and uninvited guests: autophagyrelated pathways in cellular defense. Cell, 120(2):159-162. https://doi.org/10.1016/j.cell.2005.01.005

Levine B, Klionsky DJ, 2004. Development by self-digestion: molecular mechanisms and biological functions of autophagy. Dev Cell, 6(4):463-477. https://doi.org/10.1016/s1534-5807(04)00099-1

Li L, Zhu XM, Su ZZ, et al., 2021. Insights of roles played by septins in pathogenic fungi. Virulence, 12(1):1550-1562. https://doi.org/10.1080/21505594.2021.1933370

Li XH, He SK, Ma BY, 2020. Autophagy and autophagyrelated proteins in cancer. Mol Cancer, 19:12. https://doi.org/10.1186/s12943-020-1138-4

Li XZ, Yan XH, 2019. Sensors for the mTORC1 pathway regulated by amino acids. J Zhejiang Univ-Sci B (Biomed \& Biotechnol), 20(9):699-712.

https://doi.org/10.1631/jzus.B1900181

Lin PW, Chu ML, Liu HS, 2021. Autophagy and metabolism. Kaohsiung J Med Sci, 37(1):12-19. https://doi.org/10.1002/kjm2.12299

Ling YM, Shaw MH, Ayala C, et al., 2006. Vacuolar and plasma membrane stripping and autophagic elimination of Toxoplasma gondii in primed effector macrophages. $J$ Exp Med, 203(9):2063-2071. https://doi.org/10.1084/jem.20061318

Liu D, Wu H, Wang CG, et al., 2019. STING directly activates autophagy to tune the innate immune response. Cell Death Differ, 26(9):1735-1749. https://doi.org/10.1038/s41418-018-0251-z

Liu TB, Liu XH, Lu JP, et al., 2010. The cysteine protease MoAtg4 interacts with MoAtg8 and is required for differentiation and pathogenesis in Magnaporthe oryzae. Autophagy, 6(1):74-85. https://doi.org/10.4161/auto.6.1.10438

Liu XH, Lin FC, 2008. Investigation of the biological roles of autophagy in appressorium morphogenesis in Magnaporthe oryzae. J Zhejiang Univ-Sci B (Biomed \& Biotechnol), 9(10):793-796. https://doi.org/10.1631/jzus.B0860013

Liu XH, Gao HM, Xu F, et al., 2012. Autophagy vitalizes the pathogenicity of pathogenic fungi. Autophagy, 8(10): 14151425. https://doi.org/10.4161/auto.21274

Liu XH, Zhao YH, Zhu XM, et al., 2017. Autophagy-related protein MoAtg14 is involved in differentiation, development and pathogenicity in the rice blast fungus Magnaporthe oryzae. Sci Rep, 7:40018. https://doi.org/10.1038/srep40018

Loewith R, Jacinto E, Wullschleger S, et al., 2002. Two TOR complexes, only one of which is rapamycin sensitive, have distinct roles in cell growth control. Mol Cell, 10(3):457-468. https://doi.org/10.1016/s1097-2765(02)00636-6

Loi M, Müller A, Steinbach K, et al., 2016. Macroautophagy proteins control MHC class I levels on dendritic cells and shape anti-viral $\mathrm{CD}^{+} \mathrm{T}$ cell responses. Cell Rep, 15(5):1076-1087. https://doi.org/10.1016/j.celrep.2016.04.002

Lu SL, Kuo CF, Chen HW, et al., 2015. Insufficient acidification of autophagosomes facilitates group A streptococcus 
survival and growth in endothelial cells. mBio, 6(5): e01435-15. https://doi.org/10.1128/mBio.01435-15

Lv YX, Fang L, Ding PS, et al., 2019. PI3K/Akt-Beclin1 signaling pathway positively regulates phagocytosis and negatively mediates NF- $\mathrm{KB}$-dependent inflammation in Staphylococcus aureus-infected macrophages. Biochem Biophys Res Commun, 510(2):284-289. https://doi.org/10.1016/j.bbrc.2019.01.091

Ma J, Underhill DM, 2013. $\beta$-glucan signaling connects phagocytosis to autophagy. Glycobiology, 23(9):1047-1051. https://doi.org/10.1093/glycob/cwt046

Ma J, Becker C, Lowell CA, et al., 2012. Dectin-1-triggered recruitment of light chain 3 protein to phagosomes facilitates major histocompatibility complex class II presentation of fungal-derived antigens. J Biol Chem, 287(41):3414934156. https://doi.org/10.1074/jbc.M112.382812

Maier HJ, Cottam EM, Stevenson-Leggett P, et al., 2013. Visualizing the autophagy pathway in avian cells and its application to studying infectious bronchitis virus. Autophagy, 9(4):496-509. https://doi.org/10.4161/auto.23465

Maphasa RE, Meyer M, Dube A, 2021. The macrophage response to Mycobacterium tuberculosis and opportunities for autophagy inducing nanomedicines for tuberculosis therapy. Front Cell Infect Microbiol, 10:618414. https://doi.org/10.3389/fcimb.2020.618414

Martens S, Parvanova I, Zerrahn J, et al., 2005. Disruption of Toxoplasma gondii parasitophorous vacuoles by the mouse p47-resistance GTPases. PLoS Pathog, 1(3):e24. https://doi.org/10.1371/journal.ppat.0010024

Martinez J, Almendinger J, Oberst A, et al., 2011. Microtubuleassociated protein 1 light chain 3 alpha (LC3)-associated phagocytosis is required for the efficient clearance of dead cells. Proc Natl Acad Sci USA, 108(42):17396-17401. https://doi.org/10.1073/pnas.1113421108

Martinez J, Malireddi RKS, Lu Q, et al., 2015. Molecular characterization of LC3-associated phagocytosis reveals distinct roles for Rubicon, NOX2 and autophagy proteins. Nat Cell Biol, 17(7):893-906. https://doi.org/10.1038/ncb3192

Matscheko N, Mayrhofer P, Rao YJ, et al., 2019. Atg11 tethers Atg9 vesicles to initiate selective autophagy. PLoS Biol, 17(7):e3000377. https://doi.org/10.1371/journal.pbio.3000377

Matsunaga K, Morita E, Saitoh T, et al., 2010. Autophagy requires endoplasmic reticulum targeting of the PI3kinase complex via Atg14L. J Cell Biol, 190(4):511-521. https://doi.org/10.1083/jcb.200911141

Melzer T, Duffy A, Weiss LM, et al., 2008. The gamma interferon (IFN- $\gamma$ )-inducible GTP-binding protein IGTP is necessary for Toxoplasma vacuolar disruption and induces parasite egression in IFN- $\gamma$-stimulated astrocytes. Infect Immun, 76(11):4883-4894. https://doi.org/10.1128/IAI.01288-07

Mestre MB, Colombo MI, 2012. cAMP and EPAC are key players in the regulation of the signal transduction pathway involved in the $\alpha$-hemolysin autophagic response. PLoS Pathog, 8(5):e1002664. https://doi.org/10.1371/journal.ppat.1002664

Mestre MB, Fader CM, Sola C, et al., 2010. $\alpha$-Hemolysin is required for the activation of the autophagic pathway in Staphylococcus aureus infected cells. Autophagy, 6(1): 110-125.

https://doi.org/10.4161/auto.6.1.10698

Mijaljica D, Prescott M, Devenish RJ, 2011. Microautophagy in mammalian cells: revisiting a 40-year-old conundrum. Autophagy, 7(7):673-682.

https://doi.org/10.4161/auto.7.7.14733

Min JS, Kim DE, Jin YH, et al., 2020. Kurarinone inhibits $\mathrm{HCoV}-\mathrm{OC} 43$ infection by impairing the virus-induced autophagic flux in MRC-5 human lung cells. J Clin Med, 9(7):2230. https://doi.org/10.3390/jcm9072230

Miramón P, Dunker C, Windecker H, et al., 2012. Cellular responses of Candida albicans to phagocytosis and the extracellular activities of neutrophils are critical to counteract carbohydrate starvation, oxidative and nitrosative stress. PLOS ONE, 7(12):e52850. https://doi.org/10.1371/journal.pone.0052850

Mitchell G, Ge L, Huang QY, et al., 2015. Avoidance of autophagy mediated by PlcA or ActA is required for Listeria monocytogenes growth in macrophages. Infect Immun, 83(5):2175-2184. https://doi.org/10.1128/IAI.00110-15

Mizushima N, Komatsu M, 2011. Autophagy: renovation of cells and tissues. Cell, 147(4):728-741. https://doi.org/10.1016/j.cell.2011.10.026

Mogensen TH, Paludan SR, 2001. Molecular pathways in virus-induced cytokine production. Microbiol Mol Biol Rev, 65(1):131-150. https://doi.org/10.1128/MMBR.65.1.131-150.2001

Mostowy S, 2013. Autophagy and bacterial clearance: a not so clear picture. Cell Microbiol, 15(3):395-402. https://doi.org/10.1111/cmi.12063

Nakagawa I, Amano A, Mizushima N, et al., 2004. Autophagy defends cells against invading group A Streptococcus. Science, 306(5698):1037-1040. https://doi.org/10.1126/science.1103966

Narendra D, Tanaka A, Suen DF, et al., 2008. Parkin is recruited selectively to impaired mitochondria and promotes their autophagy. J Cell Biol, 183(5):795-803. https://doi.org/10.1083/jcb.200809125

Neumann Y, Bruns SA, Rohde M, et al., 2016. Intracellular Staphylococcus aureus eludes selective autophagy by activating a host cell kinase. Autophagy, 12(11):2069-2084. https://doi.org/10.1080/15548627.2016.1226732

Nicola AM, Albuquerque P, Martinez LR, et al., 2012. Macrophage autophagy in immunity to Cryptococcus neoformans and Candida albicans. Infect Immun, 80(9): 3065-3076. https://doi.org/10.1128/IAI.00358-12

Noad J, von der Malsburg A, Pathe C, et al., 2017. LUBACsynthesized linear ubiquitin chains restrict cytosol-invading bacteria by activating autophagy and NF- $\mathrm{KB}$. Nat Microbiol, 
2(7):17063.

https://doi.org/10.1038/nmicrobiol.2017.63

Obara K, Ohsumi Y, 2011. PtdIns 3-kinase orchestrates autophagosome formation in yeast. J Lipids, 2011:498768. https://doi.org/10.1155/2011/498768

Ogawa M, Mimuro H, Yoshikawa Y, et al., 2011. Manipulation of autophagy by bacteria for their own benefit. Microbiol Immunol, 55(7):459-471. https://doi.org/10.1111/j.1348-0421.2011.00343.x

Öhman T, Teirilä L, Lahesmaa-Korpinen AM, et al., 2014. Dectin-1 pathway activates robust autophagy-dependent unconventional protein secretion in human macrophages. J Immunol, 192(12):5952-5962. https://doi.org/10.4049/jimmunol.1303213

Ohshima J, Lee Y, Sasai M, et al., 2014. Role of mouse and human autophagy proteins in IFN- $\gamma$-induced cell-autonomous responses against Toxoplasma gondii. J Immunol, 192(7): 3328-3335. https://doi.org/10.4049/jimmunol.1302822

Okamoto S, Nagase S, 2018. Pathogenic mechanisms of invasive group a Streptococcus infections by influenza virus-group A Streptococcus superinfection. Microbiol Immunol, 62(3):141-149. https://doi.org/10.1111/1348-0421.12577

Orvedahl A, Levine B, 2008. Viral evasion of autophagy. Autophagy, 4(3):280-285. https://doi.org/10.4161/auto.5289

Otto M, 2014. Staphylococcus aureus toxins. Curr Opin Microbiol, 17:32-37. https://doi.org/10.1016/j.mib.2013.11.004

Pauwels AM, Trost M, Beyaert R, et al., 2017. Patterns, receptors, and signals: regulation of phagosome maturation. Trends Immunol, 38(6):407-422. https://doi.org/10.1016/j.it.2017.03.006

Ploen D, Hildt E, 2015. Hepatitis C virus comes for dinner: how the hepatitis $\mathrm{C}$ virus interferes with autophagy. World $J$ Gastroenterol, 21(28):8492-8507. https://doi.org/10.3748/wjg.v21.i28.8492

Polajnar M, Dietz MS, Heilemann M, et al., 2017. Expanding the host cell ubiquitylation machinery targeting cytosolic Salmonella. EMBO Rep, 18(9):1572-1585. https://doi.org/10.15252/embr.201643851

Portes J, Barrias E, Travassos R, et al., 2020. Toxoplasma gondii mechanisms of entry into host cells. Front Cell Infect Microbiol, 10:294. https://doi.org/10.3389/fcimb.2020.00294

Prentice E, Jerome WG, Yoshimori T, et al., 2004a. Coronavirus replication complex formation utilizes components of cellular autophagy. J Biol Chem, 279(11):10136-10141. https://doi.org/10.1074/jbc.M306124200

Prentice E, McAuliffe J, Lu XT, et al., 2004b. Identification and characterization of severe acute respiratory syndrome coronavirus replicase proteins. J Virol, 78(18):9977-9986. https://doi.org/10.1128/JVI.78.18.9977-9986.2004

Py BF, Lipinski MM, Yuan JY, 2007. Autophagy limits Listeria monocytogenes intracellular growth in the early phase of primary infection. Autophagy, 3(2):117-125. https://doi.org/10.4161/auto.3618
Queval CJ, Brosch R, Simeone R, 2017. The macrophage: a disputed fortress in the battle against Mycobacterium tuberculosis. Front Microbiol, 8:2284. https://doi.org/10.3389/fmicb.2017.02284

Raught B, Gingras AC, Sonenberg N, 2001. The target of rapamycin (TOR) proteins. Proc Natl Acad Sci USA, 98(13):7037-7044.

https://doi.org/10.1073/pnas.121145898

Ravenhill BJ, Boyle KB, von Muhlinen N, et al., 2019. The cargo receptor NDP52 initiates selective autophagy by recruiting the ULK complex to cytosol-invading bacteria. Mol Cell, 74(2):320-329.e6. https://doi.org/10.1016/j.molcel.2019.01.041

Reggiori F, Tucker KA, Stromhaug PE, et al., 2004. The Atg1Atg13 complex regulates Atg9 and Atg23 retrieval transport from the pre-autophagosomal structure. Dev Cell, 6(1):79-90. https://doi.org/10.1016/s1534-5807(03)00402-7

Reggiori F, Monastyrska I, Shintani T, et al., 2005a. The actin cytoskeleton is required for selective types of autophagy, but not nonspecific autophagy, in the yeast Saccharomyces cerevisiae. Mol Biol Cell, 16(12):5843-5856. https://doi.org/10.1091/mbc.e05-07-0629

Reggiori F, Shintani T, Chong H, et al., 2005b. Atg9 cycles between mitochondria and the pre-autophagosomal structure in yeasts. Autophagy, 1(2):101-109. https://doi.org/10.4161/auto.1.2.1840

Reggiori F, Monastyrska I, Verheije MH, et al., 2010. Coronaviruses hijack the LC3-I-positive edemosomes, ER-derived vesicles exporting short-lived ERAD regulators, for replication. Cell Host Microbe, 7(6):500-508. https://doi.org/10.1016/j.chom.2010.05.013

Reggiori F, Komatsu M, Finley K, et al., 2012. Autophagy: more than a nonselective pathway. Int J Cell Biol, 2012: 219625. https://doi.org/10.1155/2012/219625

Richards AL, Jackson WT, 2012. Intracellular vesicle acidification promotes maturation of infectious poliovirus particles. PLoS Pathog, 8(11):e1003046. https://doi.org/10.1371/journal.ppat.1003046

Romano PS, Arboit MA, Vázquez CL, et al., 2009. The autophagic pathway is a key component in the lysosomal dependent entry of Trypanosoma cruzi into the host cell. Autophagy, 5(1):6-18. https://doi.org/10.4161/auto.5.1.7160

Rudkin FM, Bain JM, Walls C, et al., 2013. Altered dynamics of Candida albicans phagocytosis by macrophages and PMNs when both phagocyte subsets are present. mBio, 4(6):e00810-13. https://doi.org/10.1128/mBio.00810-13

Rudnicka W, Kaczmarek M, Szeliga J, et al., 1997. The host response to Listeria monocytogenes mutants defective in genes encoding phospholipases $\mathrm{C}(\mathrm{plc} A, \mathrm{plcB})$ and actin assembly (actA). Microbiol Immunol, 41(11):847-853. https://doi.org/10.1111/j.1348-0421.1997.tb01939.x

Ruland J, Hartjes L, 2019. CARD-BCL-10-MALT1 signalling in protective and pathological immunity. Nat Rev Immunol, 19(2):118-134. https://doi.org/10.1038/s41577-018-0087-2 
Sakurai A, Maruyama F, Funao J, et al., 2010. Specific behavior of intracellular Streptococcus pyogenes that has undergone autophagic degradation is associated with bacterial streptolysin $\mathrm{O}$ and host small $\mathrm{G}$ proteins Rab5 and Rab7. J Biol Chem, 285(29):22666-22675. https://doi.org/10.1074/jbc.M109.100131

Salassa BN, Romano PS, 2019. Autophagy: a necessary process during the Trypanosoma cruzi life-cycle. Virulence, 10(1): 460-469. https://doi.org/10.1080/21505594.2018.1543517

Salazar F, Brown GD, 2018. Antifungal innate immunity: a perspective from the last 10 years. J Innate Immun, 10(5-6): 373-397. https://doi.org/10.1159/000488539

Sanjuan MA, Dillon CP, Tait SWG, et al., 2007. Toll-like receptor signalling in macrophages links the autophagy pathway to phagocytosis. Nature, 450(7173):1253-1257. https://doi.org/10.1038/nature06421

Sasai M, Yamamoto M, 2019. Innate, adaptive, and cellautonomous immunity against Toxoplasma gondii infection. Exp Mol Med, 51(12):1-10. https://doi.org/10.1038/s12276-019-0353-9

Schille S, Crauwels P, Bohn R, et al., 2018. LC3-associated phagocytosis in microbial pathogenesis. Int J Med Microbiol, 308(1):228-236. https://doi.org/10.1016/j.ijmm.2017.10.014

Schnaith A, Kashkar H, Leggio SA, et al., 2007. Staphylococcus aureus subvert autophagy for induction of caspaseindependent host cell death. $J$ Biol Chem, 282(4):26952706. https://doi.org/10.1074/jbc.M609784200

Schneider M, Ackermann K, Stuart M, et al., 2012. Severe acute respiratory syndrome coronavirus replication is severely impaired by MG132 due to proteasome-independent inhibition of m-calpain. J Virol, 86(18):10112-10122. https://doi.org/10.1128/JVI.01001-12

Schuck S, 2020. Microautophagy-distinct molecular mechanisms handle cargoes of many sizes. J Cell Sci, 133(17):jcs246322. https://doi.org/10.1242/jcs.246322

Scott SV, Guan J, Hutchins MU, et al., 2001. Cvt19 is a receptor for the cytoplasm-to-vacuole targeting pathway. Mol Cell, 7(6):1131-1141. https://doi.org/10.1016/s1097-2765(01)00263-5

Sekito T, Kawamata T, Ichikawa R, et al., 2009. Atg17 recruits Atg9 to organize the pre-autophagosomal structure. Genes Cells, 14(5):525-538.

https://doi.org/10.1111/j.1365-2443.2009.01299.x

Shi CS, Kehrl JH, 2008. MyD88 and Trif target Beclin 1 to trigger autophagy in macrophages. $J$ Biol Chem, 283(48): 33175-33182. https://doi.org/10.1074/jbc.M804478200

Shintani T, Klionsky DJ, 2004a. Autophagy in health and disease: a double-edged sword. Science, 306(5698):990-995. https://doi.org/10.1126/science.1099993

Shintani T, Klionsky DJ, 2004b. Cargo proteins facilitate the formation of transport vesicles in the cytoplasm to vacuole targeting pathway. J Biol Chem, 279(29):29889-29894. https://doi.org/10.1074/jbc.M404399200
Shroff A, Sequeira R, Patel V, et al., 2018. Knockout of autophagy gene, ATG5 in mice vaginal cells abrogates cytokine response and pathogen clearance during vaginal infection of Candida albicans. Cell Immunol, 324:59-73. https://doi.org/10.1016/j.cellimm.2017.12.012

Smeekens SP, Malireddi RK, Plantinga TS, et al., 2014. Autophagy is redundant for the host defense against systemic Candida albicans infections. Eur J Clin Microbiol Infect Dis, 33(5):711-722. https://doi.org/10.1007/s10096-013-2002-x

Snijder EJ, van der Meer Y, Zevenhoven-Dobbe J, et al., 2006. Ultrastructure and origin of membrane vesicles associated with the severe acute respiratory syndrome coronavirus replication complex. J Virol, 80(12):5927-5940. https://doi.org/10.1128/JVI.02501-05

Stévenin V, Chang YY, le Toquin Y, et al., 2019. Dynamic growth and shrinkage of the Salmonella-containing vacuole determines the intracellular pathogen niche. Cell Rep, 29(12):3958-3973.e7. https://doi.org/10.1016/j.celrep.2019.11.049

Subauste CS, 2019. Interplay between Toxoplasma gondii, autophagy, and autophagy proteins. Front Cell Infect Microbiol, 9:139.

https://doi.org/10.3389/fcimb.2019.00139

Sudhakar P, Jacomin AC, Hautefort I, et al., 2019. Targeted interplay between bacterial pathogens and host autophagy. Autophagy, 15(9):1620-1633. https://doi.org/10.1080/15548627.2019.1590519

Tam JM, Mansour MK, Khan NS, et al., 2014. Dectin-1dependent LC3 recruitment to phagosomes enhances fungicidal activity in macrophages. $J$ Infect Dis, 210(11): 1844-1854. https://doi.org/10.1093/infdis/jiu290

Tang J, Lin GX, Langdon WY, et al., 2018. Regulation of Ctype lectin receptor-mediated antifungal immunity. Front Immunol, 9:123. https://doi.org/10.3389/fimmu.2018.00123

Tanida I, Ueno T, Kominami E, 2008. LC3 and autophagy. Methods Mol Biol, 445:77-88. https://doi.org/10.1007/978-1-59745-157-4_4

Tekirdag K, Cuervo AM, 2018. Chaperone-mediated autophagy and endosomal microautophagy: jointed by a chaperone. J Biol Chem, 293(15):5414-5424. https://doi.org/10.1074/jbc.R117.818237

Thurston TLM, Wandel MP, von Muhlinen N, et al., 2012. Galectin 8 targets damaged vesicles for autophagy to defend cells against bacterial invasion. Nature, 482(7385):414-418. https://doi.org/10.1038/nature10744

Tian XJ, Gala U, Zhang YP, et al., 2015. A voltage-gated calcium channel regulates lysosomal fusion with endosomes and autophagosomes and is required for neuronal homeostasis. PLoS Biol, 13(3):e1002103. https://doi.org/10.1371/journal.pbio.1002103

Towers CG, Thorburn A, 2016. Therapeutic targeting of autophagy. EBioMedicine, 14:15-23. https://doi.org/10.1016/j.ebiom.2016.10.034

Upadhyay S, Philips JA, 2019. LC3-associated phagocytosis: host defense and microbial response. Curr Opin Immunol, 
60:81-90.

https://doi.org/10.1016/j.coi.2019.04.012

Vita GM, de Simone G, Leboffe L, et al., 2020. Human serum albumin binds streptolysin O (SLO) toxin produced by group a Streptococcus and inhibits its cytotoxic and hemolytic effects. Front Immunol, 11:507092. https://doi.org/10.3389/fimmu.2020.507092

Wang Y, Qin ZH, 2013. Coordination of autophagy with other cellular activities. Acta Pharmacol Sin, 34(5):585-594. https://doi.org/10.1038/aps.2012.194

Wang YB, Weiss LM, Orlofsky A, 2009. Host cell autophagy is induced by Toxoplasma gondii and contributes to parasite growth. J Biol Chem, 284(3):1694-1701. https://doi.org/10.1074/jbc.M807890200

Wen N, Lv Q, Du ZG, 2020. MicroRNAs involved in drug resistance of breast cancer by regulating autophagy. $J$ Zhejiang Univ-Sci B (Biomed \& Biotechnol), 21(9): 690-702. https://doi.org/10.1631/jzus.B2000076

Wieczorek M, Abualrous ET, Sticht J, et al., 2017. Major histocompatibility complex (MHC) class I and MHC class II proteins: conformational plasticity in antigen presentation. Front Immunol, 8:292. https://doi.org/10.3389/fimmu.2017.00292

Wu MY, Lu JH, 2019. Autophagy and macrophage functions: inflammatory response and phagocytosis. Cells, 9(1):70. https://doi.org/10.3390/cells9010070

Xie ZP, Nair U, Klionsky DJ, 2008. Atg8 controls phagophore expansion during autophagosome formation. Mol Biol Cell, 19(8):3290-3298. https://doi.org/10.1091/mbc.E07-12-1292

Xiong QH, Yang M, Li P, et al., 2019. Bacteria exploit autophagy for their own benefit. Infect Drug Resist, 12: 3205-3215. https://doi.org/10.2147/IDR.S220376

Yamamoto H, Kakuta S, Watanabe TM, et al., 2012. Atg9 vesicles are an important membrane source during early steps of autophagosome formation. J Cell Biol, 198(2):219-233. https://doi.org/10.1083/jcb.201202061

Yamasaki A, Watanabe Y, Adachi W, et al., 2016. Structural basis for receptor-mediated selective autophagy of aminopeptidase I aggregates. Cell Rep, 16(1):19-27. https://doi.org/10.1016/j.celrep.2016.05.066

Yang YS, Kato M, Wu X, et al., 2019. Yeast ataxin-2 forms an intracellular condensate required for the inhibition of TORC1 signaling during respiratory growth. Cell, 177(3): 697-710.e17. https://doi.org/10.1016/j.cell.2019.02.043

Yi XH, Zhang B, Fu YR, et al., 2020. STAT1 and its related molecules as potential biomarkers in Mycobacterium tuberculosis infection. J Cell Mol Med, 24(5):2866-2878. https://doi.org/10.1111/jcmm.14856

Yin ZY, Pascual C, Klionsky DJ, 2016. Autophagy: machinery and regulation. Microb Cell, 3(12):588-596. https://doi.org/10.15698/mic2016.12.546

Yin ZY, Liu X, Ariosa A, et al., 2019. Psp2, a novel regulator of autophagy that promotes autophagy-related protein translation. Cell Res, 29(12):994-1008. https://doi.org/10.1038/s41422-019-0246-4

Yorimitsu T, Klionsky DJ, 2005. Autophagy: molecular machinery for self-eating. Cell Death Differ, 12(S2):15421552.

https://doi.org/10.1038/sj.cdd.4401765

Yoshikawa Y, Ogawa M, Hain T, et al., 2009. Listeria monocytogenes ActA-mediated escape from autophagic recognition. Nat Cell Biol, 11(10):1233-1240. https://doi.org/10.1038/ncb1967

Yu ZQ, Sun LL, Jiang ZD, et al., 2020. Atg38-Atg8 interaction in fission yeast establishes a positive feedback loop to promote autophagy. Autophagy, 16(11):2036-2051. https://doi.org/10.1080/15548627.2020.1713644

Yuan WP, Strømhaug PE, Dunn WA, 1999. Glucose-induced autophagy of peroxisomes in Pichia pastoris requires a unique E1-like protein. Mol Biol Cell, 10(5):1353-1366. https://doi.org/10.1091/mbc.10.5.1353

Zachari M, Ganley IG, 2017. The mammalian ULK1 complex and autophagy initiation. Essays Biochem, 61(6):585-596. https://doi.org/10.1042/EBC20170021

Zare-Bidaki M, Hakimi H, Abdollahi SH, et al., 2014. TLR4 in toxoplasmosis; friends or foe? Microb Pathog, 69-70: 28-32.

https://doi.org/10.1016/j.micpath.2014.03.006

Zhai WJ, Wu FJ, Zhang YY, et al., 2019. The immune escape mechanisms of Mycobacterium tuberculosis. Int $\mathrm{J} \mathrm{Mol}$ Sci, 20(2):340. https://doi.org/10.3390/ijms20020340

Zhang XW, Bai XC, Chen ZJ, 2020. Structures and mechanisms in the cGAS-STING innate immunity pathway. Immunity, 53(1):43-53. https://doi.org/10.1016/j.immuni.2020.05.013

Zhao MM, Wang RS, Zhou YL, et al., 2020. Emerging relationship between RNA helicases and autophagy. $J$ Zhejiang Univ-Sci B (Biomed \& Biotechnol), 21(10): 767-778.

https://doi.org/10.1631/jzus.B2000245

Zhao ZJ, Thackray LB, Miller BC, et al., 2007. Coronavirus replication does not require the autophagy gene ATG5. Autophagy, 3(6):581-585. https://doi.org/10.4161/auto.4782

Zhao ZJ, Fux B, Goodwin M, et al., 2008. Autophagosomeindependent essential function for the autophagy protein Atg5 in cellular immunity to intracellular pathogens. Cell Host Microbe, 4(5):458-469. https://doi.org/10.1016/j.chom.2008.10.003

Zhu LQ, Mou CX, Yang X, et al., 2016. Mitophagy in TGEV infection counteracts oxidative stress and apoptosis. Oncotarget, 7(19):27122-27141. https://doi.org/10.18632/oncotarget.8345

Zhu XM, Li L, Wu M, et al., 2019. Current opinions on autophagy in pathogenicity of fungi. Virulence, 10(1): 481-489. https://doi.org/10.1080/21505594.2018.1551011

Zientara-Rytter K, Subramani S, 2020. Mechanistic insights into the role of Atg11 in selective autophagy. $\mathrm{J} \mathrm{Mol} \mathrm{Biol,}$ 432(1):104-122. https://doi.org/10.1016/j.jmb.2019.06.017 